Design, Setup, and Operation of the Deployable TeleEngineering Communications System

Jeffrey L. Williamson, Carroll J. Smith, Larry N. Lynch, and Jeff Powell 
The contents of this report are not to be used for advertising, publication, or promotional purposes. Citation of trade names does not constitute an official endorsement or approval of the use of such commercial products.

The findings of this report are not to be construed as an official Department of the Army position, unless so designated by other authorized documents. 


\title{
Design, Setup, and Operation of the Deployable TeleEngineering Communications System
}

\author{
by Jeffrey L. Williamson, Carroll J. Smith, Larry N. Lynch \\ Geotechnical and Structures Laboratory \\ U.S. Army Engineer Research and Development Center \\ 3909 Halls Ferry Road \\ Vicksburg, MS 39180-6199 \\ Jeff Powell \\ Information Technology Laboratory \\ U.S. Army Engineer Research and Development Center \\ 3909 Halls Ferry Road \\ Vicksburg, MS 39180-6199
}

Final report

Approved for public release; distribution is unlimited 


\section{Contents}

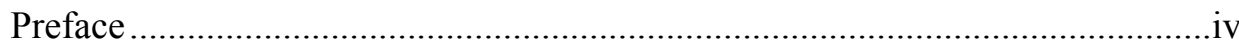

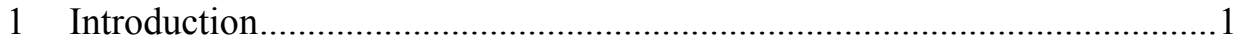

2 - Components/Packaging of the Deployable System .......................................2

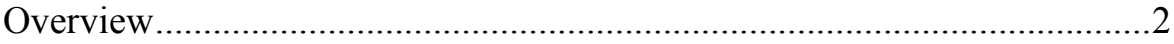

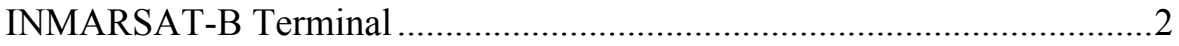

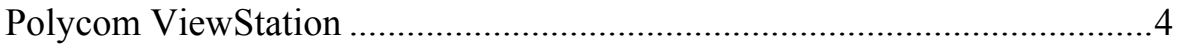

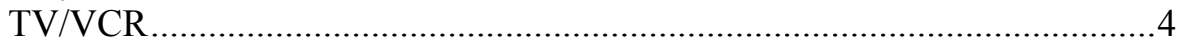

SPOCC

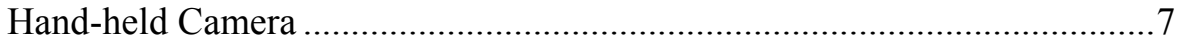

KIV-7HS, Switchbox, Cables, and Miscellaneous Parts ...............................

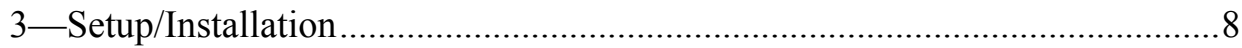

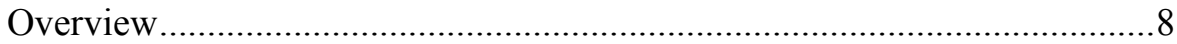

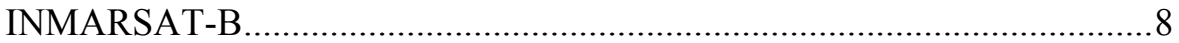

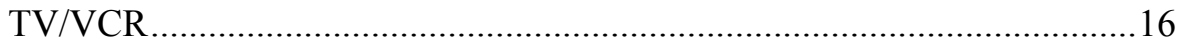

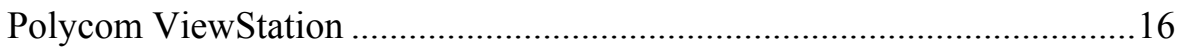

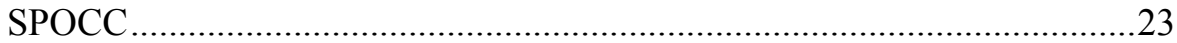

KIV-7HS, Switchbox, Cables, and Miscellaneous Parts .............................26

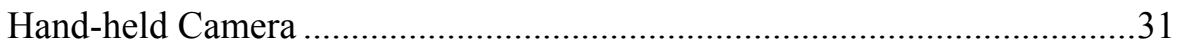

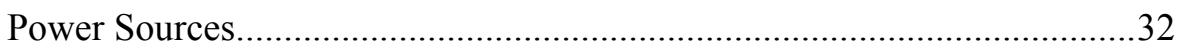

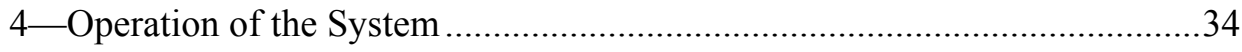

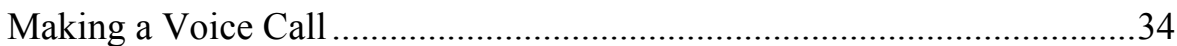

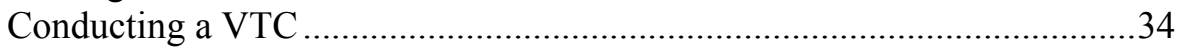

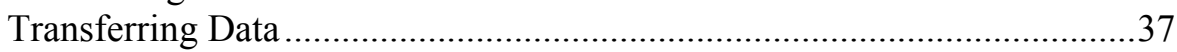

Digital Pictures (Hand-held Camera) ........................................................... 41

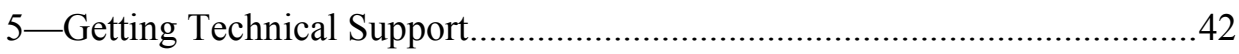

SF 298 


\section{Preface}

The work reported herein was funded under the TeleEngineering Operations Technology Demonstration Program, Research, Development, Testing, and Evaluation direct allotted funds, U.S. Army Engineer Research and Development Center (ERDC), Vicksburg, MS. Messrs. Carroll Smith, Jeffrey L. Williamson, Dr. Larry Lynch, Geotechnical and Structures Laboratory (GSL), and Mr. Jeff Powell, Information Technology Laboratory (ITL), performed the work.

The work at ERDC was performed under the general supervision of Dr. David W. Pittman, Chief, Airfields and Pavements Division, GSL, Dr. William Willoughby, Acting Chief, Mobility Systems Division, GSL, Dr. Charles R. Welch, Chief, Instrumentation Systems Division, ITL, Mr. Tim Ables, Acting Director, ITL, Dr. William F. Marcuson, Director (retired), Geotechnical Laboratory, and Dr. Michael O'Connor, Director, GSL, and Dr. Bryant Matter, Director Emeritus, GSL.

At the time of publication of this report, Dr. James R. Houston was Director of ERDC, and COL John W. Morris III, EN, was Commander and Executive Director.

The contents of this report are not to be used for advertising, publication, or promotional purposes. Citation of trade names does not constitute an official endorsement or approval of the use of such commercial products. 


\section{Introduction}

In FY97, the U.S. Army Engineer Research and Development Center (ERDC) initiated a technology demonstration program to determine the feasibility of providing deployed troops direct access to subject matter experts (SME). Direct access to the SME would allow responses to engineering challenges beyond the in-theater capability to be provided without the time delays and costs associated with deploying the SME to the theater.

During the execution of the technology demonstration, the ERDC TeleEngineering Operations Center (TEOC) was established as the main operations center from which TeleEngineering support would be provided to the deployed force. Shortly after the establishment of the TEOC, the U.S. Army Engineer Division, North Atlantic (NAD) requested TeleEngineering support for operations in the Balkans region. In addition to engineer analysis support, the TEOC was requested to develop a method for deployed U.S. Army Corps of Engineers (USACE) personnel to communicate with the U.S. Army Engineer District, Europe (NAU), NAD, and the TEOC. The requirements for the communications equipment were: (a) deployability and (b) the capability to allow secure and nonsecure data transfer, voice, and video teleconferencing (VTC). Additionally, the TEOC was requested to provide a fixed-site TeleEngineering Communications System to be used at NAU, NAD, and the TEOC. The fixed-site system, which interfaces with an Integrated Systems Digital Network (ISDN) line, is described in a separate report.

The TEOC requested that the ERDC Information Technology Laboratory (ITL) take the lead in developing the communications system. Within a 3-week period, ITL and TEOC personnel researched, designed, procured, validated, and transferred the satellite-based deployed system and the ISDN-based fixed-site system to NAU for deployment.

The purpose of this report is to describe the various components of the deployable TeleEngineering communications systems and to provide the step-bystep procedures required to set up and operate the system. Chapter 2 presents the components that comprise the system and describes how the components are packaged for shipment. Chapter 3 provides details for setting up the equipment, the interconnections between the individual components, and providing power to the system. The operation of the system (i.e., making a voice call, conducting a VTC, transferring data, and using a hand-held digital camera) is presented in Chapter 4; methods of receiving technical support are provided in Chapter 5. 


\section{Components/Packaging of the Deployable System}

\section{Overview}

Components of the deployable system are packaged in seven separate containers or cases for ease of transporting to remote sites and to reduce the risk of damage to the equipment during shipment.

The seven cases are described as follows:

a. International Maritime Satellite - B (INMARSAT-B) terminal.

b. Polycom ViewStation.

c. Secure Portable Operations Communications Center (SPOCC).

d. TV/VCR combination.

e. Digital video/still camera.

f. KIV-7HS encryption device, switchbox w/cables, power conversion hardware, miscellaneous.

g. Software and documentation.

The color, construction, and size of some cases may vary from those cases in Figure 1. Components of the TeleEngineering (TE) deployable system are described in the following sections.

\section{INMARSAT-B Terminal}

The INMARSAT-B terminal is packaged in a large, black, airtight case. Equipment contained in this case provides satellite communications with other TE communication systems and provides voice communications as a stand-alone package. The remainder of the TE equipment (VTC and data transfer components and encryption device) connect to this terminal. 


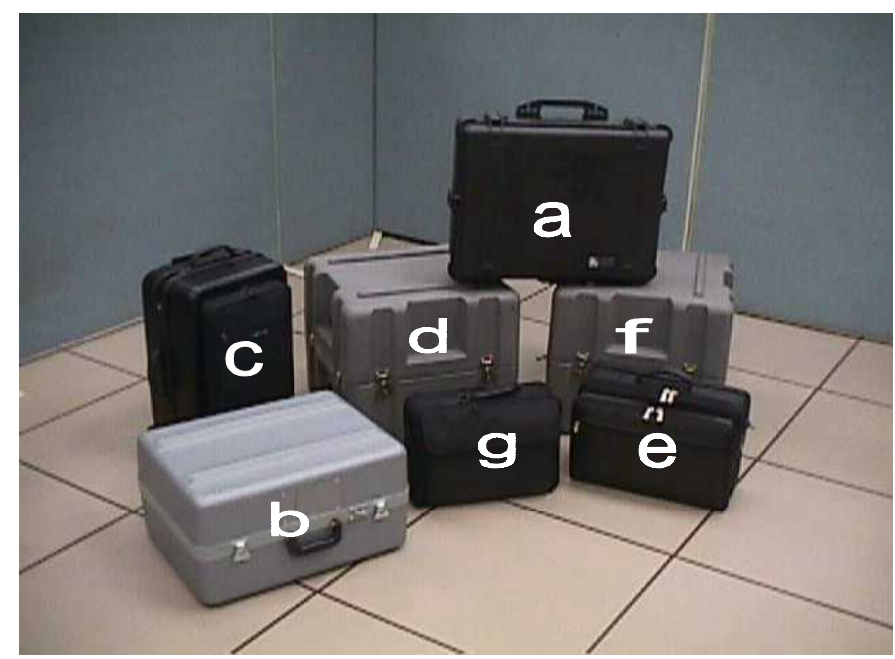

Figure 1. The seven cases of the deployable system

The INMARSAT-B equipment (Figure 2) within the case consists of five major components:

a. The mobile terminal indoor unit (IDU).

b. Antenna stand outdoor unit (ODU).

c. Four antenna panels.

d. Power supply.

e. Antenna cable.

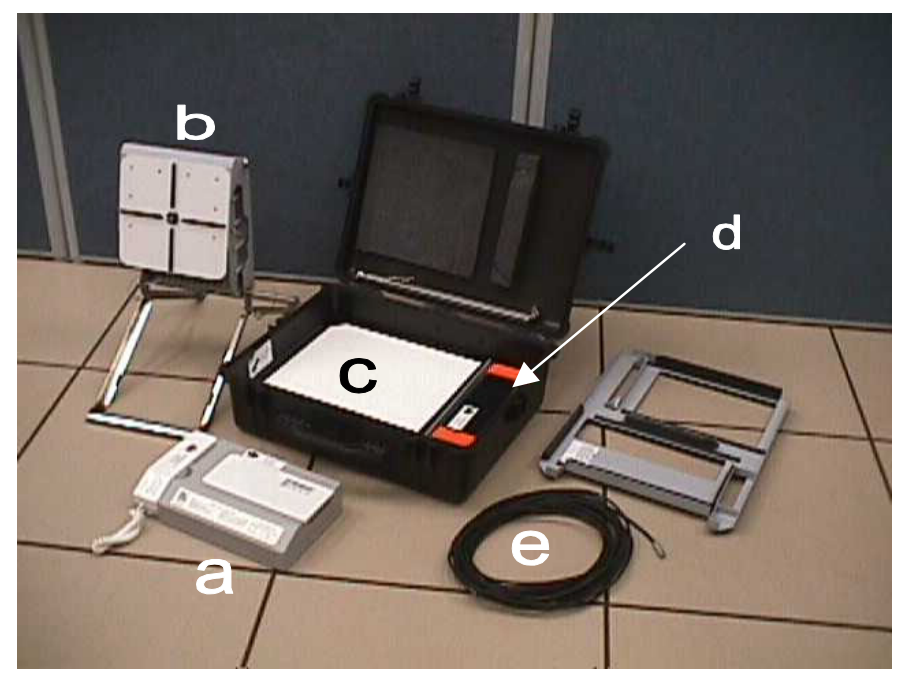

Figure 2. INMARSAT-B terminal 
Other components in the case include two power cables, a metal plate for packaging purposes, and an instruction guide for setting up and repacking the satellite terminal. Two leveling legs for the ODU are stored in the lid of the container; they are used to level the stand when it is placed on a sloped surface.

When repacking the equipment, ensure that all packing "warnings" are followed to ensure that cables and connectors are not damaged.

\section{Polycom ViewStation}

The Polycom ViewStation (also referred to herein as the "Polycom" or "ViewStation") shown in Figure 3 is a versatile video unit which is interoperable with the INMARSAT-B system. The ViewStation included in the TE communications equipment uses V.35 protocol which supports secure communications.

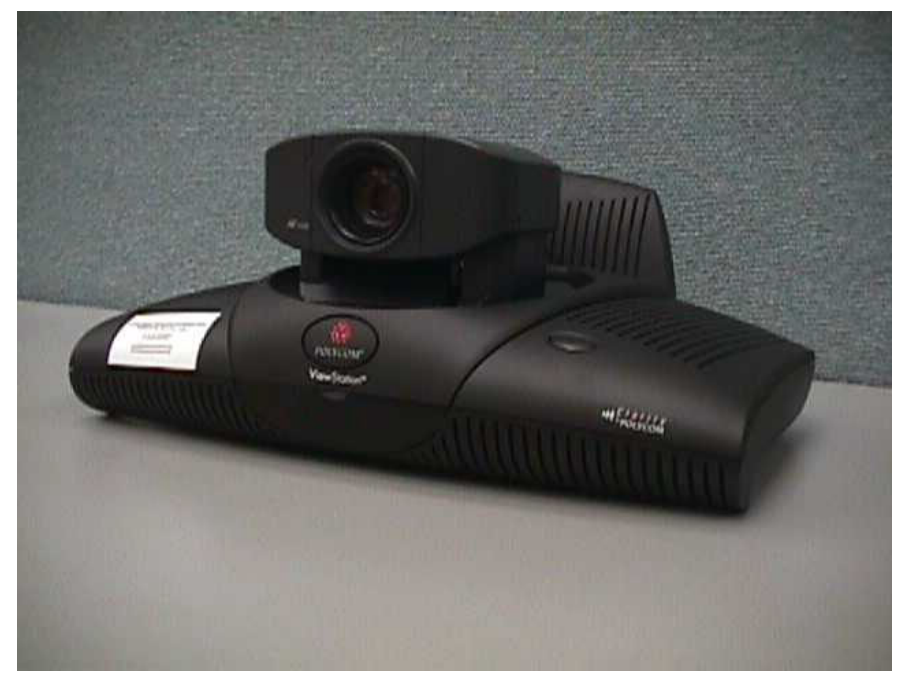

Figure 3. Polycom ViewStation

The ViewStation can be connected to the TV/VCR combination and separate hand-held camera to enhance the TE VTC communications. The plastic housing of the ViewStation is designed to rest on top of a TV, as shown in Figure 4.

Cable connections on the rear of the Polycom ViewStation are color-coded to ease the task of connecting it to other equipment.

\section{TV/VCR}

The 33-cm (13-in.) TV/VCR combination provided with each deployable system serves as the video monitor for the VTC system and provides the capability of recording video teleconferencing (VTC) sessions on VHS tapes. 
The standard TV/VCR provided is presented in Figure 4 with the Polycom ViewStation. It has one video input and one audio input for connection directly with the ViewStation. It is powered by $110 \mathrm{VAC}$ and is packaged in one of the large, plastic, square cases. If $220 \mathrm{VAC}$ will be used, a step-down transformer is required.

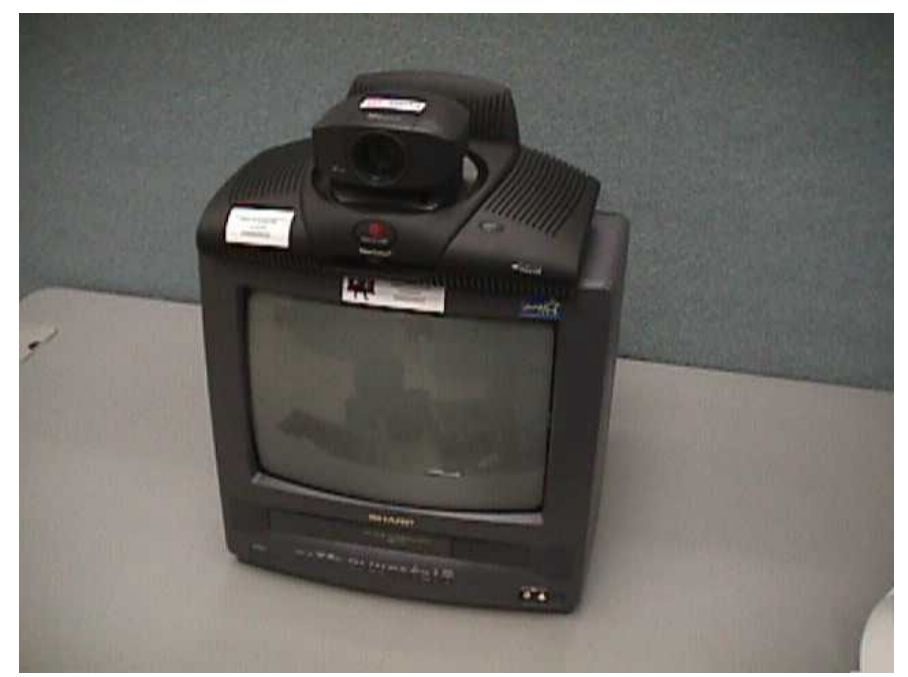

Figure 4. Polycom ViewStation resting on a TV/VCR combination

\section{SPOCC}

The SPOCC is housed in a Samsonite case; it consists of three major components: (a) laptop computer, (b) printer/scanner, and (c) uninterruptable power supply (UPS), which will accommodate various voltage sources. Power cables and other accessories are stored in zippered pouches on the side of the case. An STU-III (secure telephone) can be inserted into the SPOCC as shown in Figure 5 but is not provided with the TE system. 


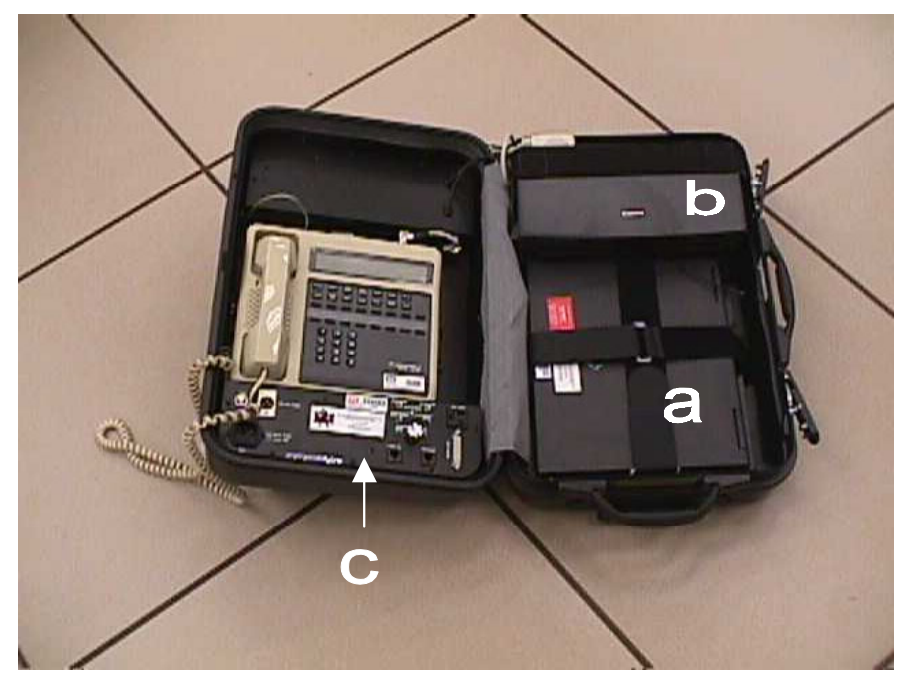

Figure 5. SPOCC components

The SPOCC can be operated from a wide range of power sources. A $220 \mathrm{VAC}$ power cord and a $110 \mathrm{~V}$ AC power cord are furnished for use, depending on the available $\mathrm{A} / \mathrm{C}$ power.

An AC receptacle is installed in the SPOCC as shown in Figure 6. This "outlet" provides the same power that is supplied to the unit; therefore, if 220 VAC is supplied, $220 \mathrm{VAC}$ will be available on this receptacle. If $110 \mathrm{VAC}$ is supplied to the SPOCC, this outlet will provide 110 VAC. Caution should be taken when operating the TV/VCR and other equipment on this receptacle to ensure that correct voltage is being supplied to the external equipment.

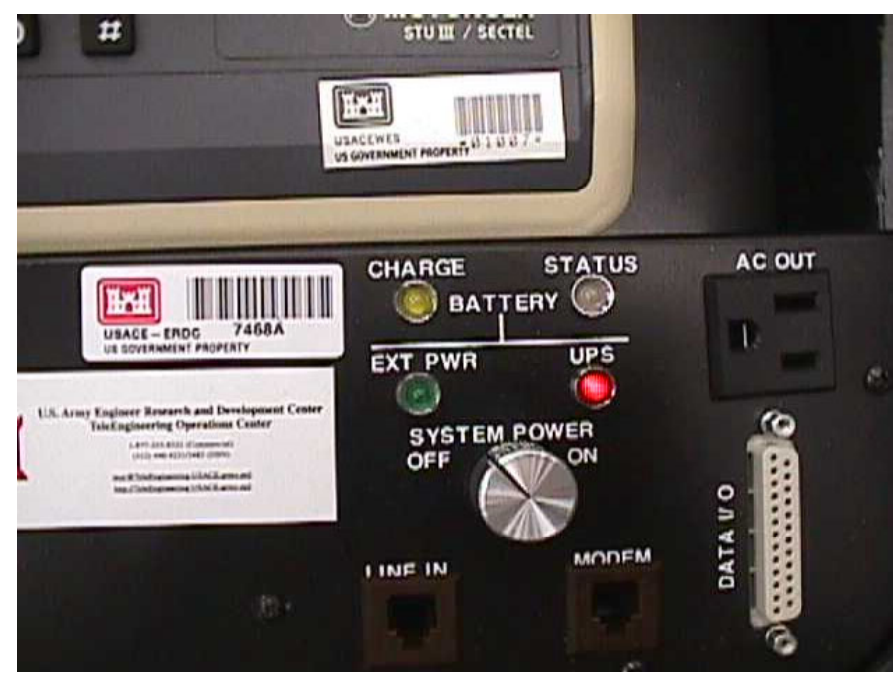

Figure 6. System power on the SPOCC

The SPOCC also has a DC input jack. The jack utilizes a power cable that can be plugged into a vehicle's cigarette lighter port or clamped onto $12 \mathrm{VDC}$ battery terminals. If a power source is unavailable, a power subsystem, the UPS, 
is included in the SPOCC. The UPS which will operate the SPOCC for a limited amount of time, using internal batteries.

\section{Hand-held Camera}

With each system, a hand-held digital video camera is provided. This camera is capable of recording digital video images, still digital images, and real-time images, both video and still. The cameras distributed with the systems may vary, depending upon availability. The camera is packaged in the soft, black leather case.

\section{KIV-7HS, Switchbox, Cables, and Miscellaneous Parts}

The KIV-7HS (commonly referred to as the "KIV") is the National Security Agency (NSA)-certified high-speed encryption device, which enables secure communications. Secure encryption keys must be electronically loaded into the KIV for secure communications. The KIV is produced by Mykotronics and requires the 5 VDC power supply provided with the system.

All necessary power cables, power strips, battery jumper cables, etc. are provided with the system. Data cables which enable communications between the INMARSAT-B terminal, the KIV, and the Viewstation or SPOCC also are provided. To facilitate switching the system between its VTC mode and its data transfer mode, and vice versa, an AB switchbox is provided. 


\section{Setup/Installation}

\section{Overview}

Subsequent sections describe the steps to unpack and set up each component. Initially, the setup instructions will provide directions for setting up the INMARSAT-B terminal. As individual components are unpacked and set up, this chapter will provide details on the cable connections between the system components. Appendix A provides a diagram illustrating the interconnections of the components.

\section{INMARSAT-B}

As the case is opened, notice the upper and lower levels of INMARSAT-B components (Figure 7). The antenna cable, IDU, and the ODU are located on the upper level; the antenna panels and power supply are stored on the lowest level.

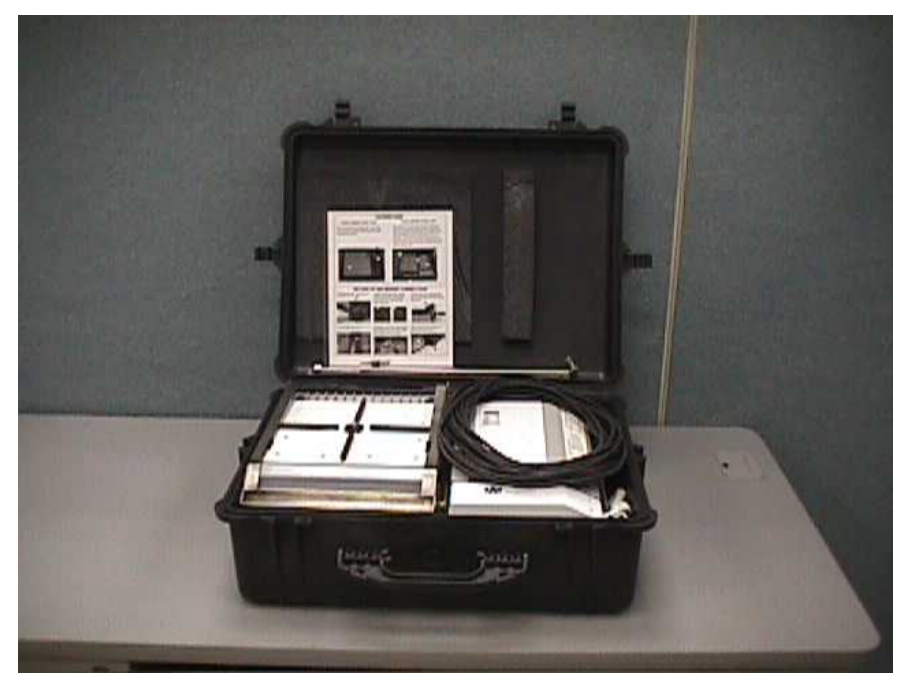

Figure 7. INMARSAT-B terminal components in case

Remove the antenna cable from the case and set aside. Next, remove the ODU from the left side of the case and unfold the legs. Secure the legs by inserting the attached pins into the front and rear leg intersections. The pins are 
secured with a thin wire cable attached to each side of the ODU near the point of insertion. The antenna base plate can be angled by loosening the wing nuts on each side of the base. An antenna base angle can be set at approximately 30 to $45 \mathrm{deg}$, as a starting point. To prevent thread damage, do not overtighten the wing nuts. Damage may also occur if the angle of the antenna baseplate is adjusted while the wing nuts are in the tightened position. Directions for obtaining an accurate angle and azimuth approximation are provided later in this chapter.

The IDU, which resembles a telephone, and the metal packing plate (or compartment separator) should be removed from the case and set aside, thus exposing the power supply and the four antenna panels. Remove the antenna panels and attach to the ODU antenna base plate as shown in Figure 8.

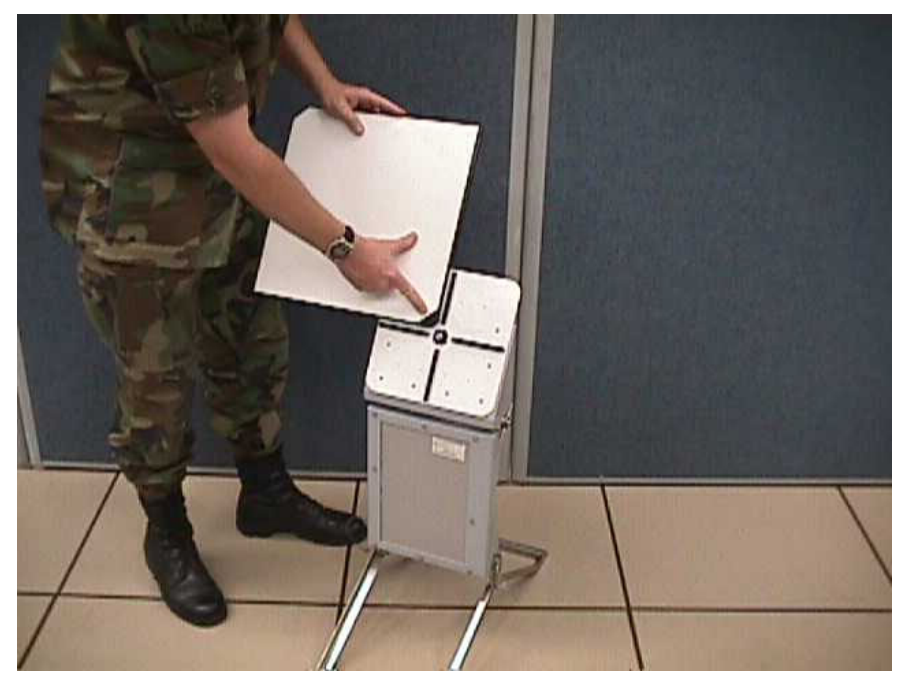

Figure 8. Attaching the antenna panels to the ODU antenna base plate

The panels are attached by sliding each panel toward the center of the base plate and locking in position with the tab located on a corner of each panel. After all antenna panels have been attached to the ODU base plate, the entire antenna ODU can be placed in a location where an unobstructed line of sight between the antenna and satellite can be obtained. Figure 9 provides a picture of the ODU after the antenna panels have been properly attached.

The antenna unit should be placed in a location that provides a clear line of sight such that signals can be received/transmitted with the satellite. Place the antenna in an area with minimum foot or vehicular traffic. Sandbags can be placed on the antenna legs to stabilize the unit.

The ODU is weatherproof. Rain and snow should not hamper its operations; however, if the antenna is to be left in place for an extended period of time, a box (constructed of wood, plastic, or fiberglass) may be constructed around it to 


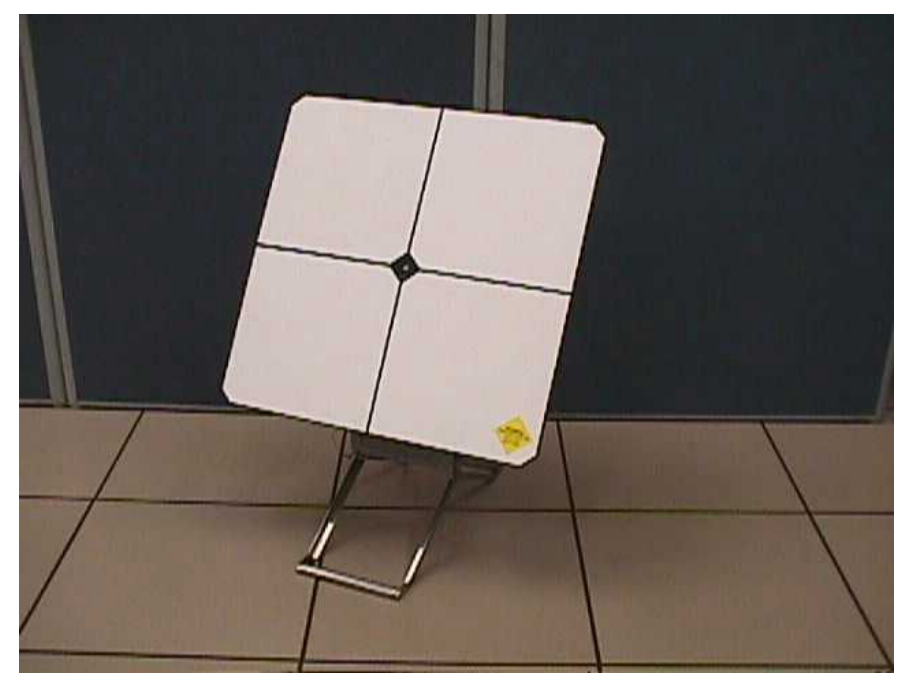

Figure 9. ODU with antenna panels attached

protect it from excessive wind and harsh weather conditions. If a box is constructed for the antenna, special care should be taken to ensure metal objects such as nails, screws, etc. are not directly in front of the antenna panels; such objects may interfere with the signal.

A warning label is located on the antenna panel indicating that personnel

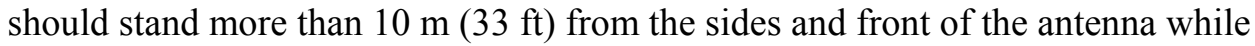
the system is in operation. The antenna possesses some safety features and will stop operating when an object remains in the path of the transmitted signal. Standing behind the antenna while the system is operating will not impede operations. The antenna does not present a safety hazard when it is not operating (i.e., when a call is not active).

Remove the power supply from the case. The power supply is designed for European and American voltages (220 VAC and $110 \mathrm{VAC}$, respectively). A power cord is furnished for each type of power; the appropriate cord should be plugged into the power source. If AC power is not available, the system can be powered at a remote site by using a 12 VDC automotive battery system and the ProSine power converter, which converts 12 VDC power to $110 \mathrm{VAC}$.

A converter, jumper cables, and power strip (Figure 10) are located in one of the larger, plastic cases. More details on the use/setup of the converter will be presented later in this chapter under a section entitled "Power Source."

With the INMARSAT-B power supply turned off, connect the gray power cord between the power supply and the IDU. The gray cord has a large connector on one end and a small connector on the other end. The connectors can only be plugged into their appropriate locations; the small connector fits the IDU and the large connector fits the power supply, as illustrated in Figure 11. Next, connect the antenna cable into the rear port on the IDU labeled "ANTENNA" (Figure 12). The other end of the cable should be plugged into the right side of the ODU (Figure 13). 


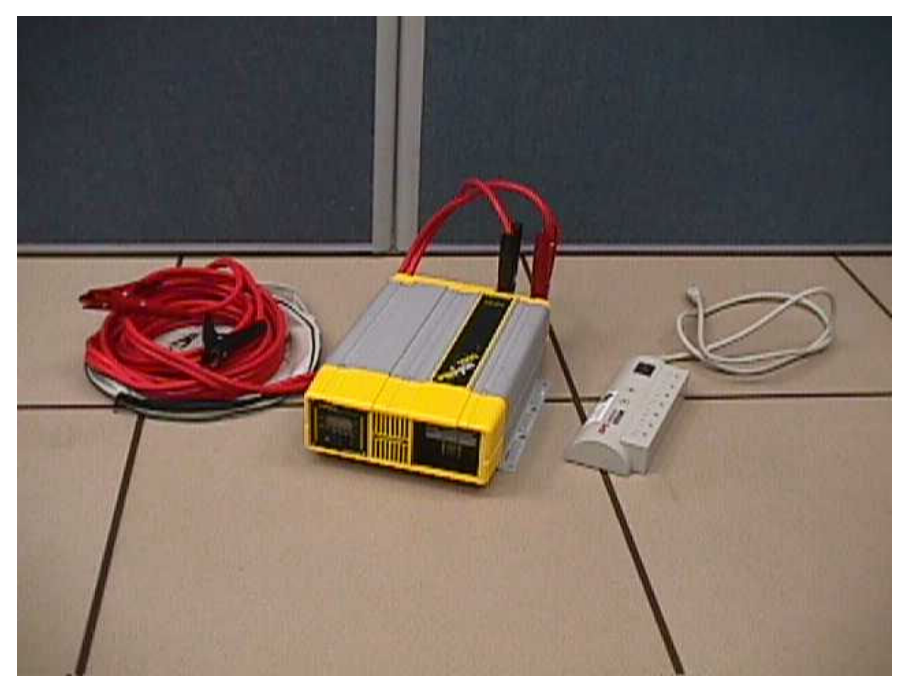

Figure 10. Battery jumper cables, ProSine power converter, and 110 VAC power strip

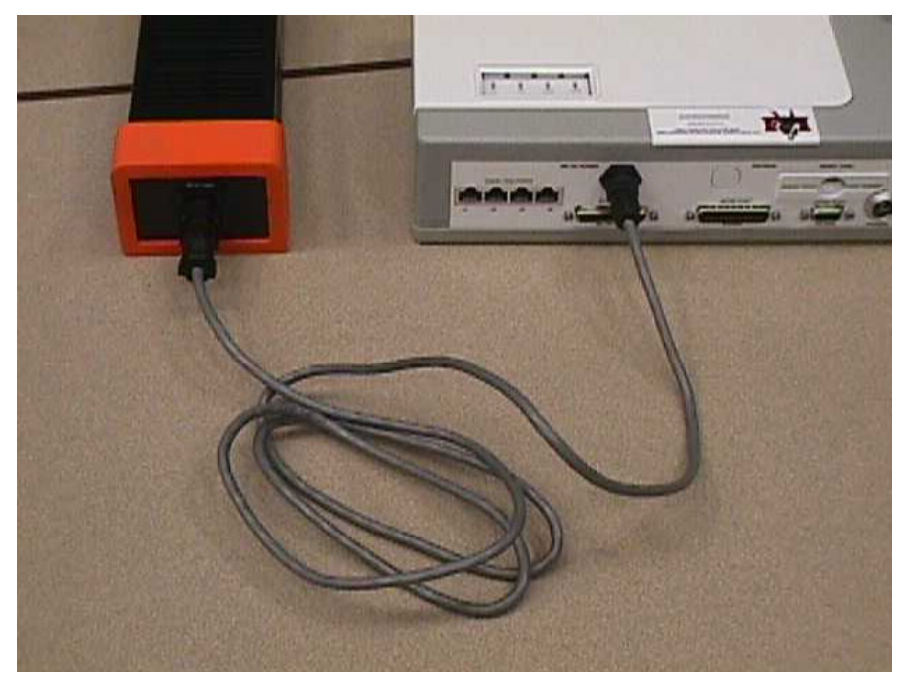

Figure 11. Power cord connection between the IDU and the INMARSAT-B power supply

Because the antenna cable connectors are identical, either end of the cable can be used for these connections. During the placement and recovery of the antenna cable, exercise caution not to kink the cable, thus causing damage to the cable and resulting in an inoperable system.

A white plastic screen protector, located on the top of the IDU, must be removed to reveal the liquid crystal display (LCD) (Figure 14) and control keys (Figure 15).

Turn on the power supply to activate the system. After the system initializes for a few moments, it will be ready for alignment. The LCD display should 


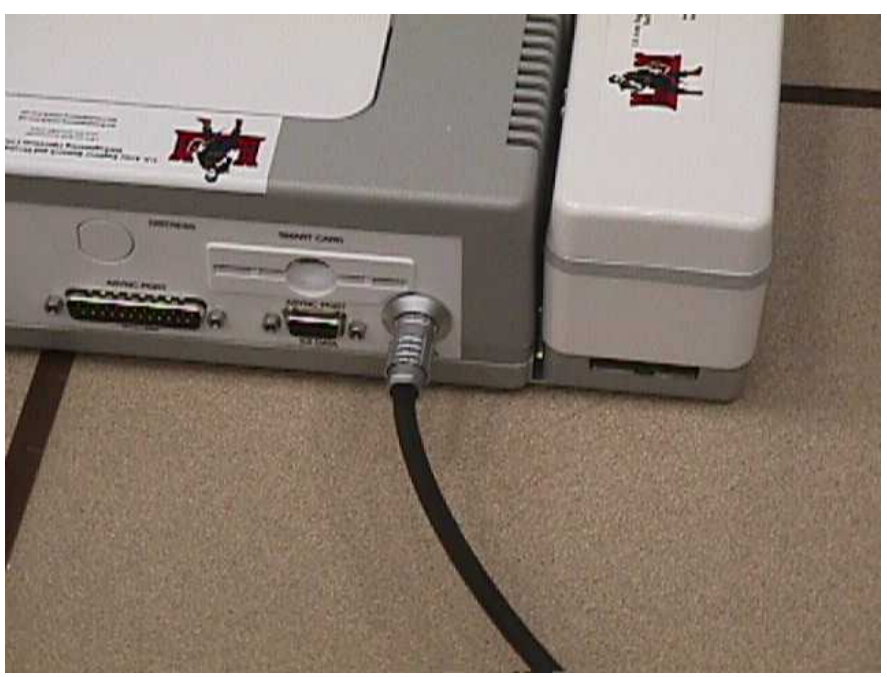

Figure 12. Antenna cable connection on the IDU

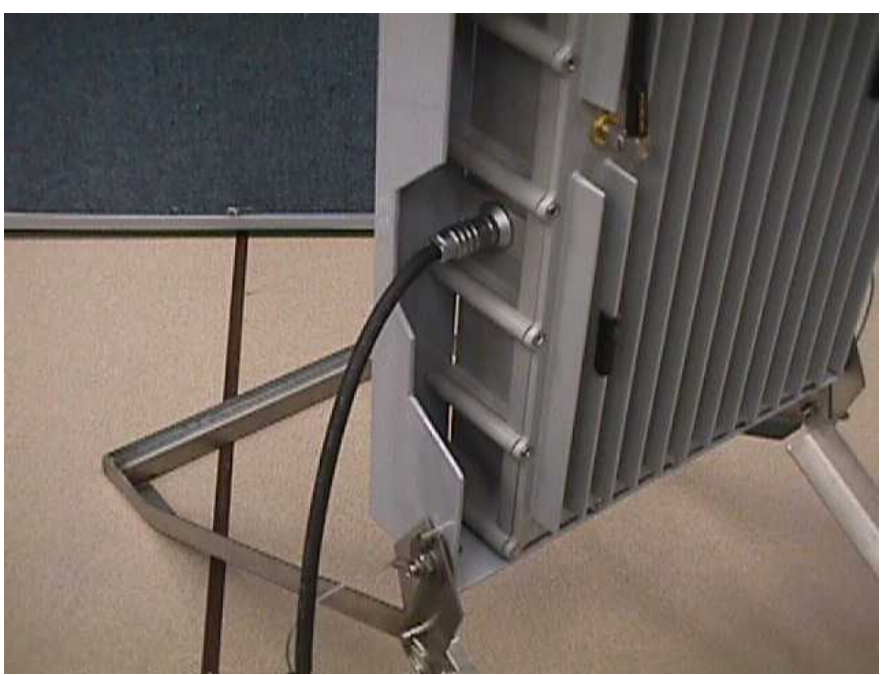

Figure 13. Antenna cable connection on the ODU

show a map of the world on the left side of the screen and system information should appear on the right side.

The user must select a satellite which provides an adequate signal. There are four available satellites: Pacific Ocean Region (POR), Indian Ocean Region (IOR), Atlantic Ocean Region West (AORW), and Atlantic Ocean Region East (AORE). Typically, a system deployed in North America will use satellite AORW, a system in Europe will use satellite AORE or IOR, and a system in Korea will use POR. Remember, the satellites' coverage or "footprints" overlap; therefore, you may be able to access two satellites from the same location. If so, simply experiment with each satellite to determine the one providing the stronger signal. 
Being able to access two satellites in an area is beneficial if the line of sight is obstructed for one satellite from your antenna's specific location. Satellites are positioned in geosynchronous orbit above the equator. Also remember, sites north of the equator will aim the antenna southward; sites located south of the equator will aim northward.

The following procedures should be followed if the satellite selection requires changing. For example, the user may need to change the satellite region from North America (AORW) to Europe (AORE). The control keys to the right of the LCD should be used to perform these changes.

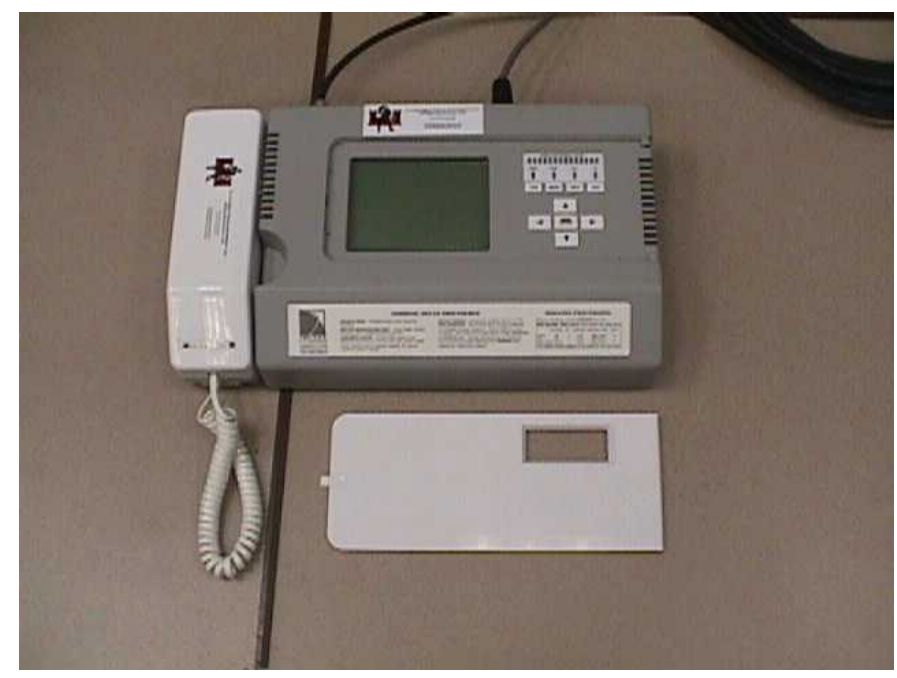

Figure 14. IDU with screen protector removed

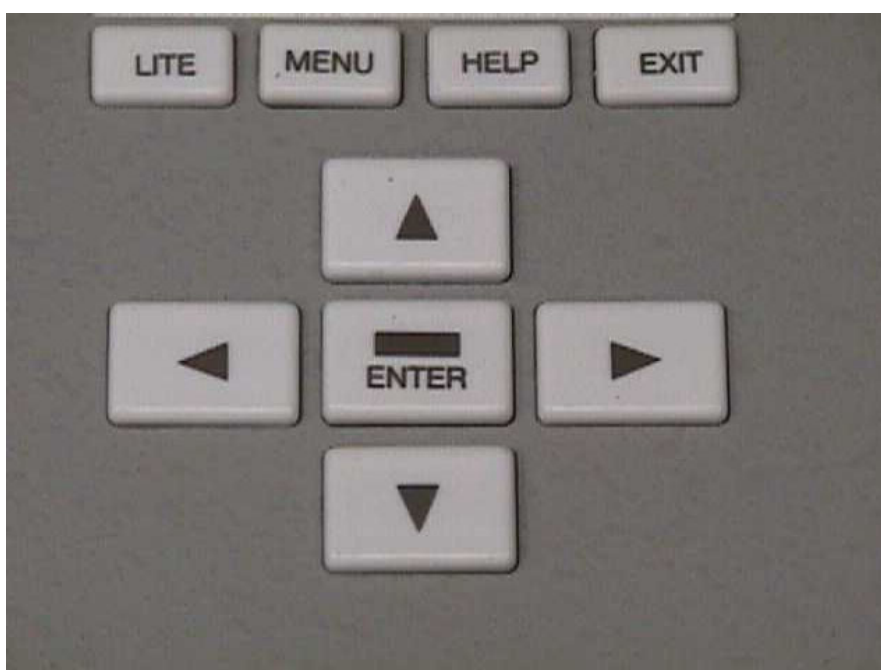

Figure 15. Control keys on the IDU

While depressing the MENU key, press the horizontal arrow keys to move the top highlighted selection to "SAT." With the MENU key still depressed, press the ENTER key to display the satellite selection screen. Highlight 
"AORE" using the arrow keys, and then depress the ENTER key. After the AORE satellite has been selected, press the EXIT key. The IDU display should indicate a satellite selection of AORE.

System status information is also shown on the LCD. The first line on the LCD indicates connectivity between the IDU and the ODU. "ODU LINK" indicates a good connection between the two units and that they are communicating properly; "ODU UNLINK" indicates otherwise. Potential problems that can cause "ODU UNLINK" are a kink in the antenna cable or a loose connection at either end of the antenna cable. The next (second) line indicates whether the system is receiving a signal from the satellite. "SAT LOCK" indicates that a signal is being received; "SAT UNLOCK" indicates otherwise.

On the third line, the message "SYS Ready" will appear when the system is registering with the satellite; otherwise, "SYS NOT RDY" will appear. Note that 3 or 4 min may be required for the system to register after being turned on.

After the display indicates an "ODU LINK," position the ODU such that a satellite lock is achieved. Before trying to position the antenna, the IDU can be used to approximate an antenna angle and direction; this is achieved by maneuvering crosshairs on the LCD screen with the arrow keys to mark the approximate location of the deployed system. For example, if the deployable site location is Vicksburg, MS, the crosshairs should be positioned on the LCD world map to approximate the location of Vicksburg. Using AORW as the selected satellite, and a deployed system location of Vicksburg, MS, the values of interest (elevation (el) and azimuth (AZ)) will be shown as el $=34 \mathrm{deg}$ and $\mathrm{AZ}=129 \mathrm{deg}$. Also, note to the right of the LCD under a heading labeled "SATELLITE SIGNAL LEVEL" (see Figure 16) the series of slotted lights (bar graph) which indicates an increase of satellite signal strength; stronger signal strengths will illuminate more Light emitting diodes (LED).

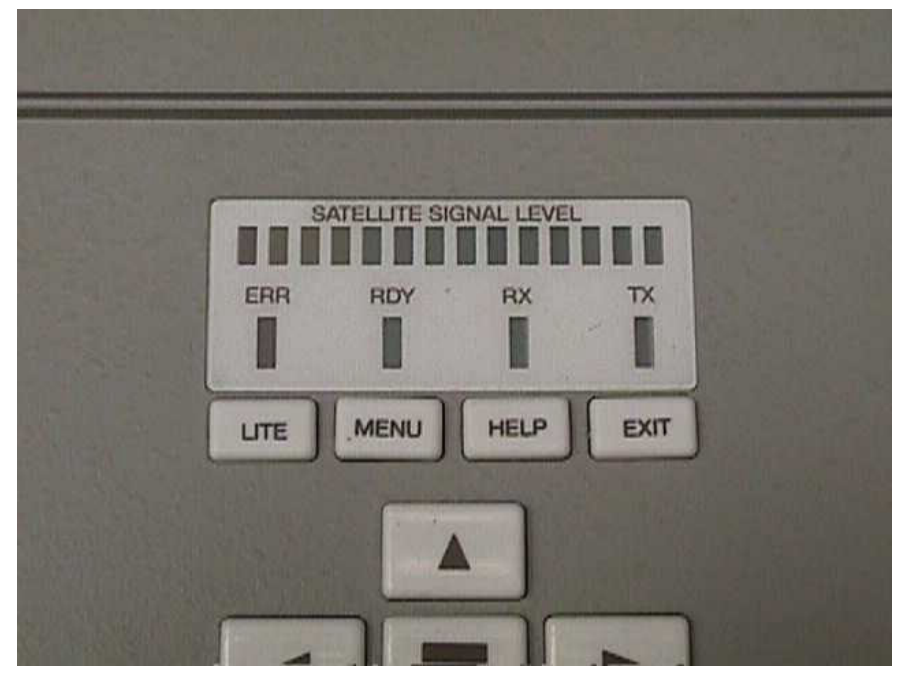

Figure 16. Satellite signal strength indicator 
The elevation or angle of the antenna is the angle measured from a perpendicular with the ground; i.e., a 0 -deg angle would require the antenna to be perpendicular with the ground, and a 90-deg angle would require the antenna to be parallel to the ground. In the example, the locking nuts should be loosened and the antenna angle should be adjusted to approximately $34 \mathrm{deg}$ and the locking nuts secured on each side of the ODU. Next, the azimuth (AZ) dictates the approximate angle to point the antenna dish, with 0 deg representing north and $180 \mathrm{deg}$ representing south. In the example, the antenna dish should be positioned to point approximately $129 \mathrm{deg}$ which equates to a southeast direction; you may also position the ODU to receive a strong satellite signal by using the approximate elevation angle and rotating the ODU by hand to locate a stronger signal. Use the green LED to accomplish this; a strong signal causes the LED to blink rapidly. The LED is located on the right rear side of the ODU under a small plastic enclosure (Figure 17).

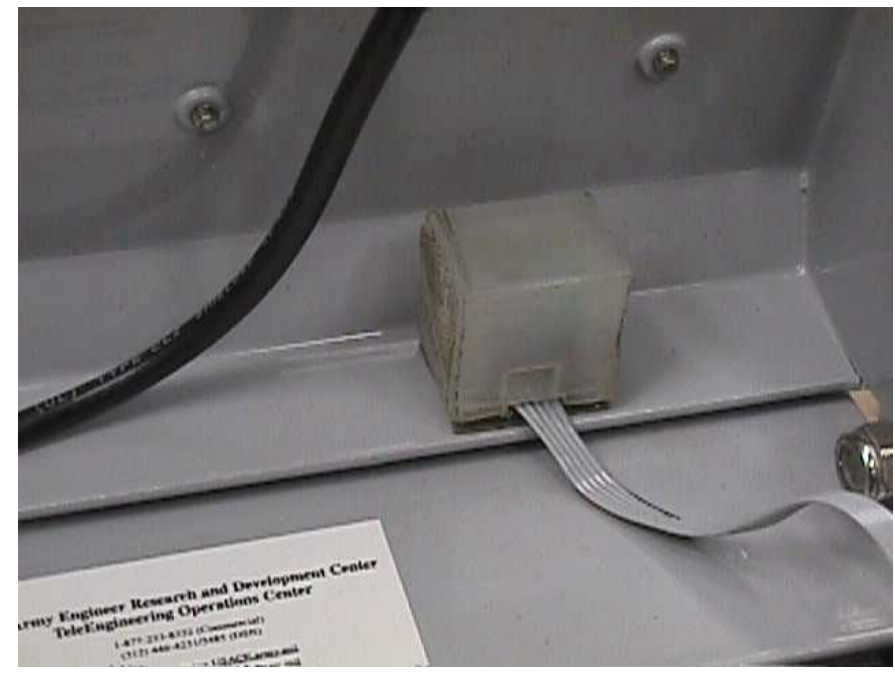

Figure 17. Signal strength LED on ODU

With the elevation angle set at approximately $34 \mathrm{deg}$, stand behind the ODU and lift the ODU; keep the ODU base level with the ground and slowly turn in a circle until a satellite signal is detected. The LED will begin to flash slowly as a weak satellite signal is detected. Continue to adjust the ODU until the signal becomes stronger (LED flashes more rapidly). As you continue to move the ODU, notice the flashing becomes slower as the satellite signal becomes weaker. Note the general azimuth of the antenna at which the signal was the strongest; try to place the antenna on the ground in this position. Always ensure that the antenna has the strongest signal possible. The angle may be adjusted as well to optimize the signal strength.

After the antenna system obtains a satellite lock, the flashing of the LED may momentarily decrease in speed while the terminal is registering itself with the satellite. In order to stabilize the ODU, place sandbags or other materials across the antenna legs. 
After the position of the antenna unit is optimized, the user should notice the IDU display and verify "SAT-LOCK" and "SYS-READY." The IDU also indicates the satellite signal strength on the bar graph LED display. Try to achieve a signal strength that shows a green segment illuminated at least four or five segments from the right end of the bar meter. A stronger signal will provide more robust communications. Only use the LED bar graph while setting up the system; the bar graph display will become erratic while the IDU is in use. The LED activity observed during operation does not indicate true signal strength.

The nonsecure satellite phone is now ready for use as a stand-alone device for voice communications.

\section{TV/VCR}

Remove the TV/VCR combination from its case. Place upon a sturdy, stable surface (tabletop, case, etc.). Remember, all equipment in the deployable system operates on dual voltage, except the TV/VCR; it operates only on $110 \mathrm{VAC}$. If the TV/VCR is used where only $220 \mathrm{VAC}$ power is available, a stepdown transformer must be used to prevent damage to the monitor. A stepdown transformer is provided with units that may need to interface with 220 VAC power sources.

\section{Polycom ViewStation}

Remove the Polycom ViewStation from its case and place it on top of the TV/VCR or other suitable location (Figure 18).

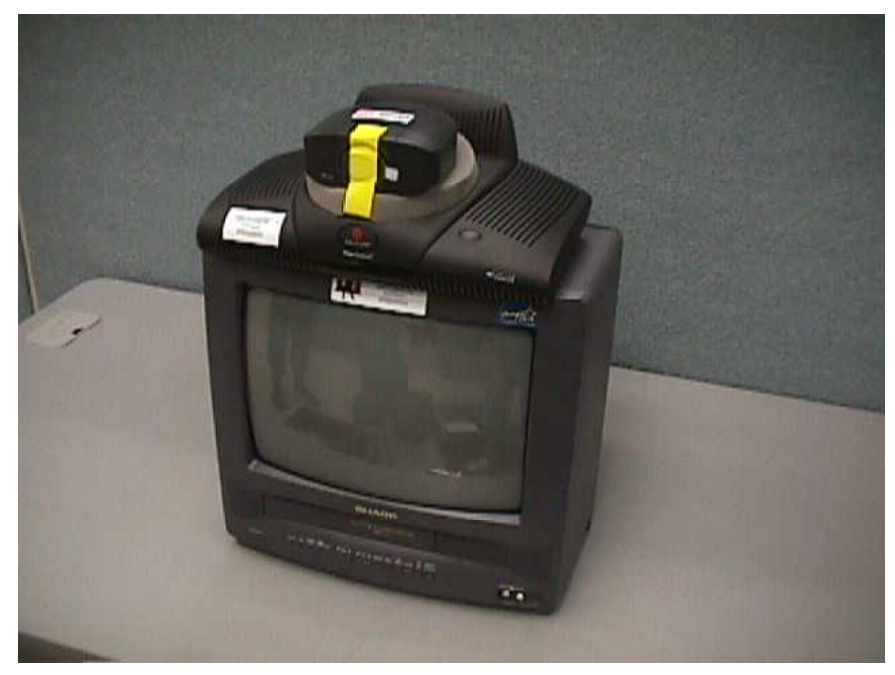

Figure 18. Polycom ViewStation position on TV/VCR combination 
The protective foam collar and clear plastic protective lens, both held in place with yellow tape, must be removed from the ViewStation's rotatable camera as shown in Figure 19.

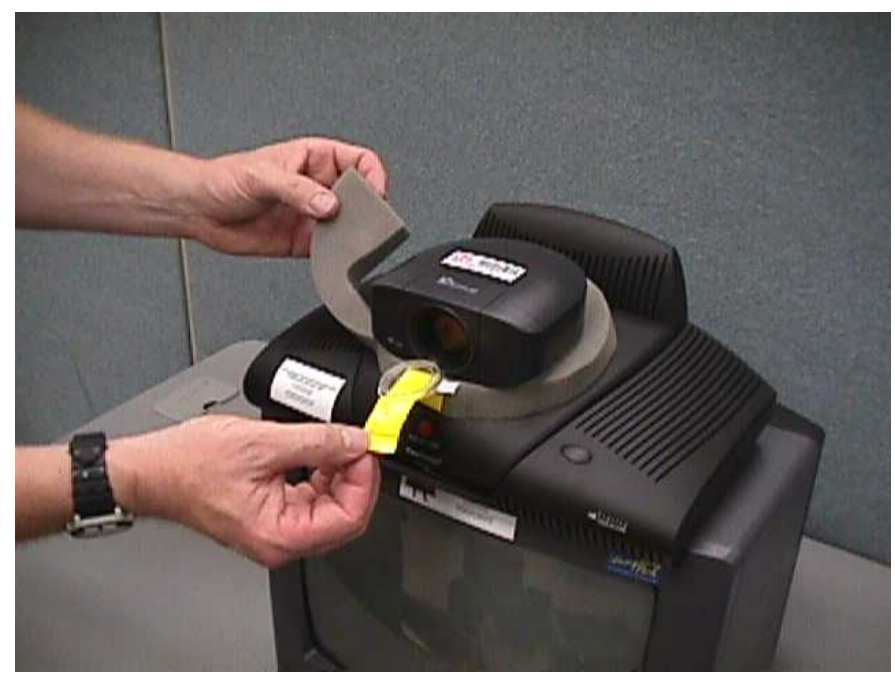

Figure 19. Removal of ViewStation's protective packaging

Remove the primary audio/visual (A/V) cable from the ViewStation case. This cable consists of four smaller cables bundled together. The connectors consist of one semiround, yellow S-video connector and three RCA connectors, each colored yellow, white, or red. Plug each of the connectors on one end of the cable into the matching color-coded jacks on the rear of the ViewStation. The four jacks are located to the right of the power jack and they are identified in a single, horizontal row with a white rectangle (Figure 20).

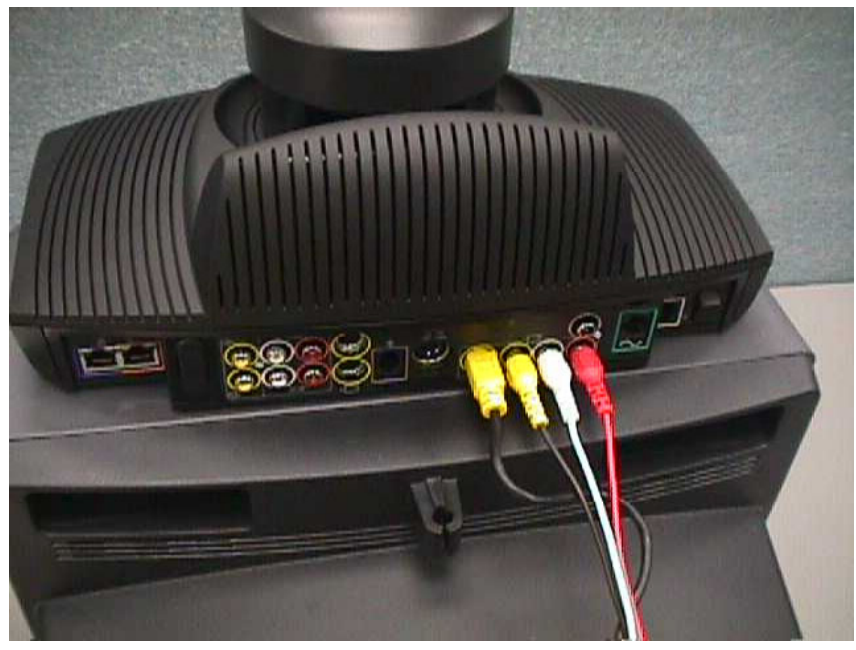

Figure 20. Connection of the primary A/V cable to the ViewStation 
Connect the cable's other end to the color-coded $\mathrm{A} / \mathrm{V}$ jacks that are located on the front of the TV/VCR, as illustrated in Figure 21. When using the TV/VCR supplied with the deployable system, it is only necessary to connect two plugs; therefore, yellow plug to yellow jack and white plug to white jack is sufficient, as shown in Figure 22. Other TV monitors may be substituted for the TV/VCR supplied with this system.

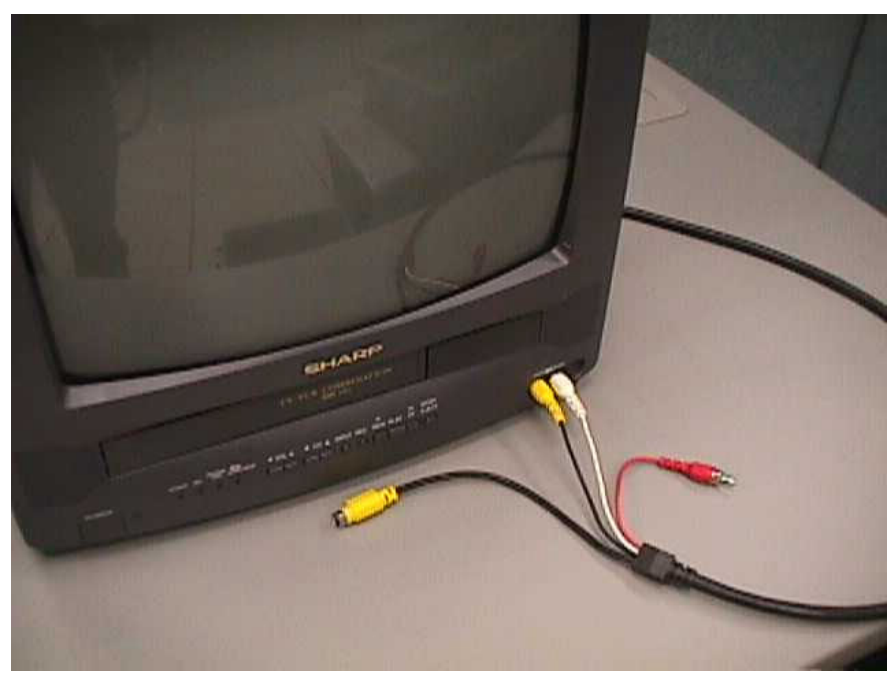

Figure 21. Connection of the primary A/V cable to the TVIVCR

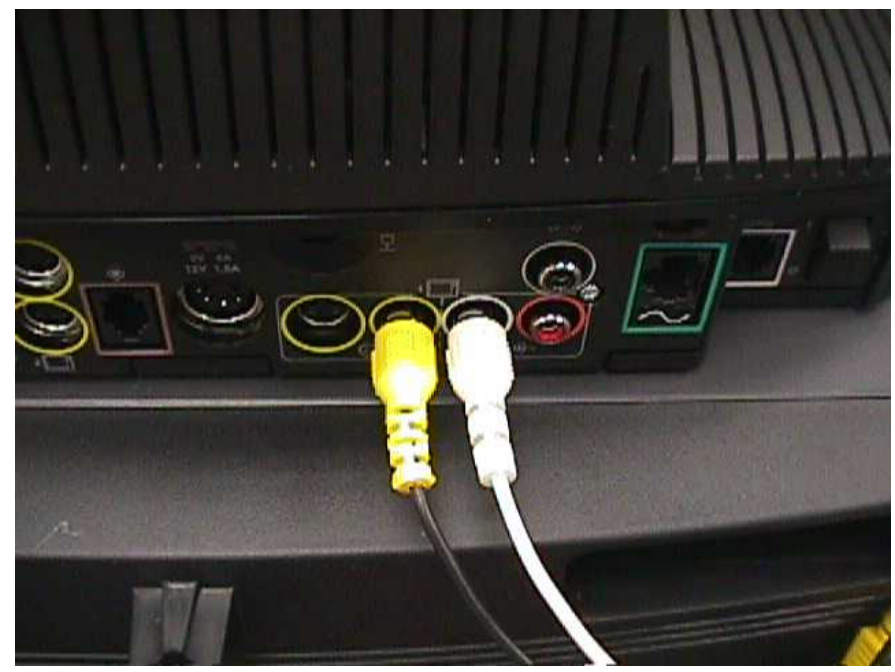

Figure 22. Connection of only two plugs on $A / V$ cable to the ViewStation

Remove the rectangular power supply box (Figure 23) from the ViewStation case, and attach to the rear of the ViewStation as shown in Figures 23, 24, and 25. Plug the circular five-pin DIN connector with a flat notch on top into the jack located on the rear center of the ViewStation. Plug the power supply 


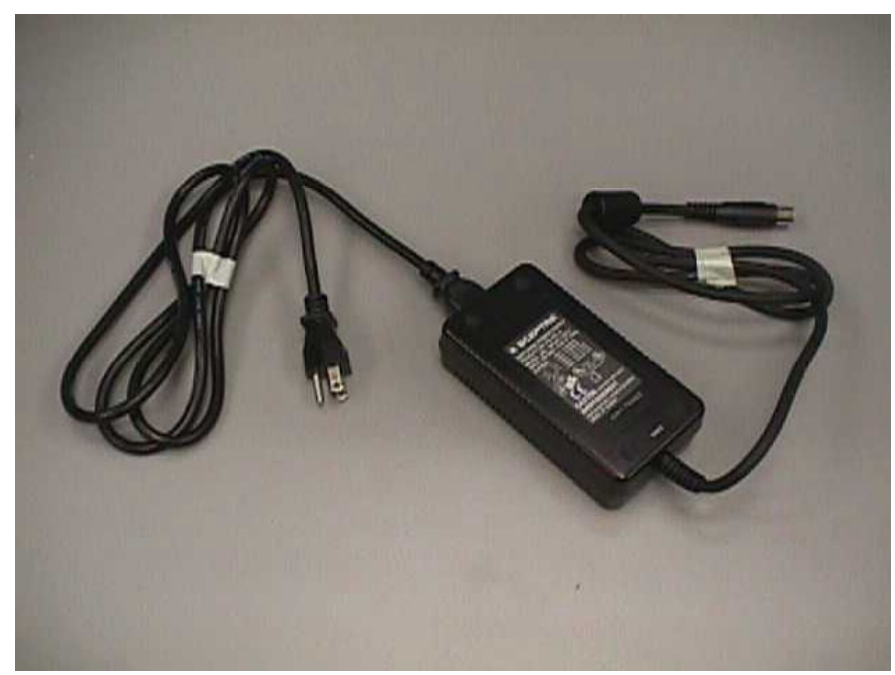

Figure 23. ViewStation power supply box

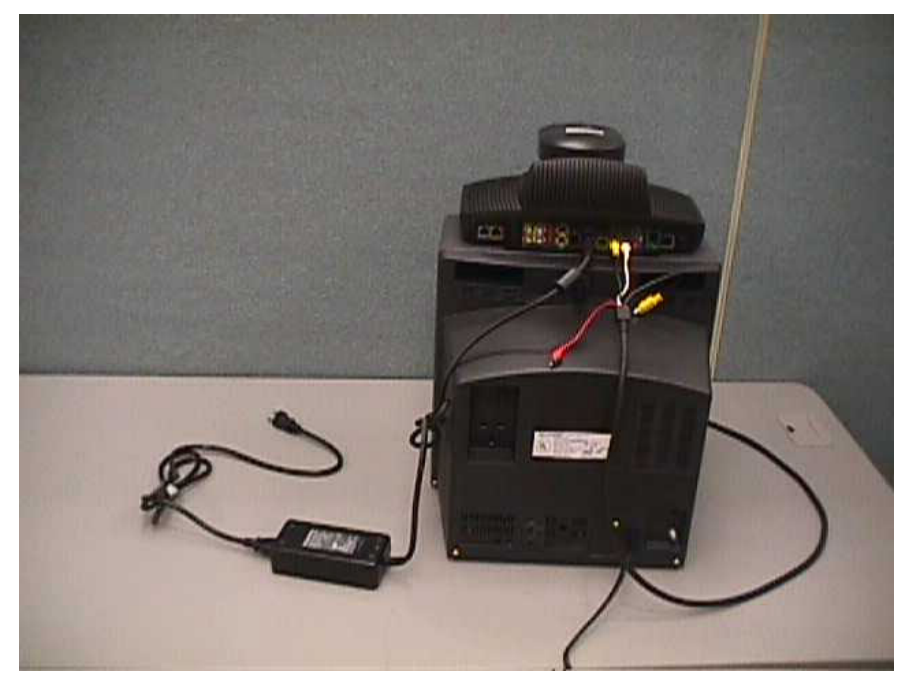

Figure 24. Connection of power supply box to ViewStation 


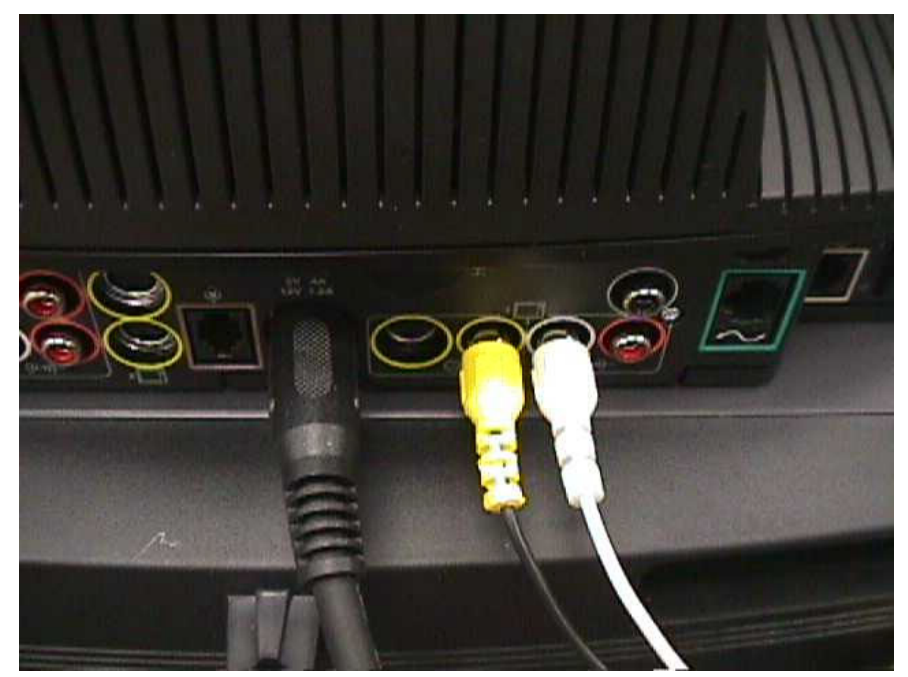

Figure 25. Close-up view of ViewStation power connection

cord on the other end of the power supply box into an appropriate AC power source. A $220 \mathrm{VAC}$ power cord and a $110 \mathrm{VAC}$ power cord are provided.

Next, remove the triangular microphone from the case and attach one end of the cable with a brown color-coded RJ11 connector (similar to a telephone connector) into the brown jack on the rear of the ViewStation as shown in Figure 26. Connect the other end of the cable to the microphone as shown in Figure 27. Figure 28 illustrates the ViewStation connections made thus far.

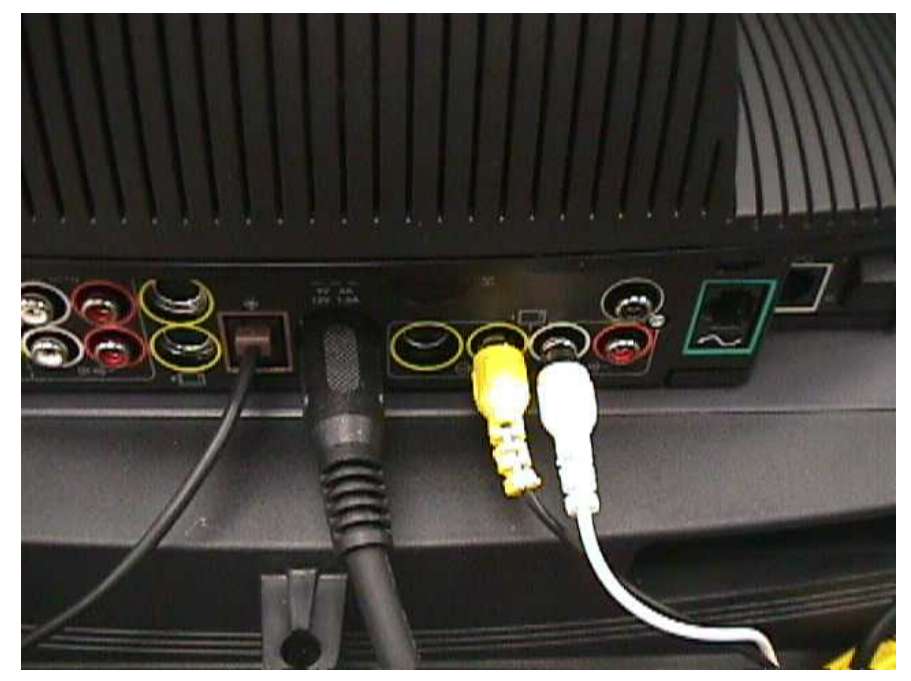

Figure 26. Microphone cable attached to ViewStation 


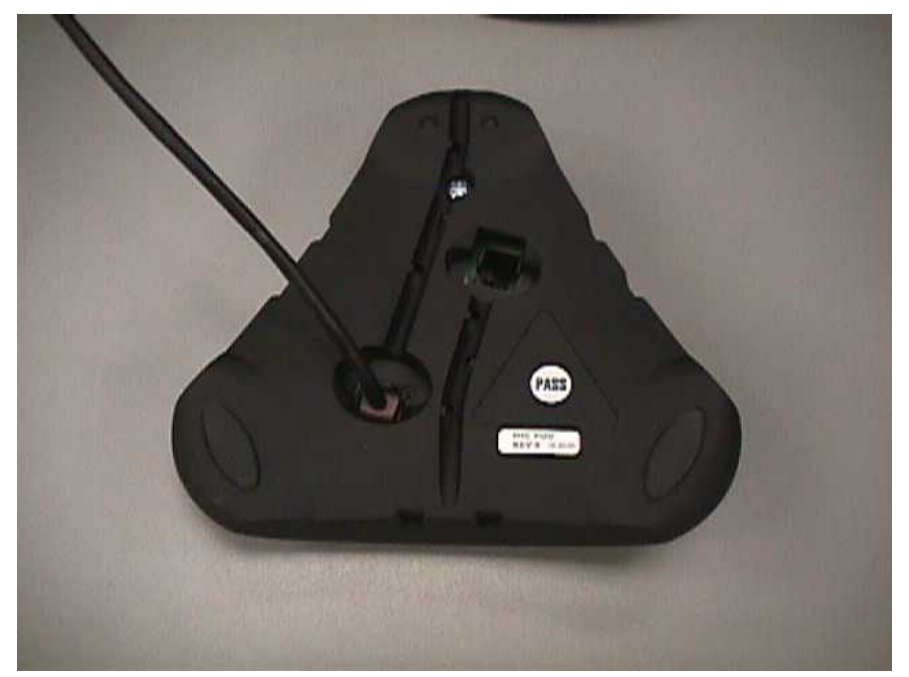

Figure 27. Microphone cable attached to microphone

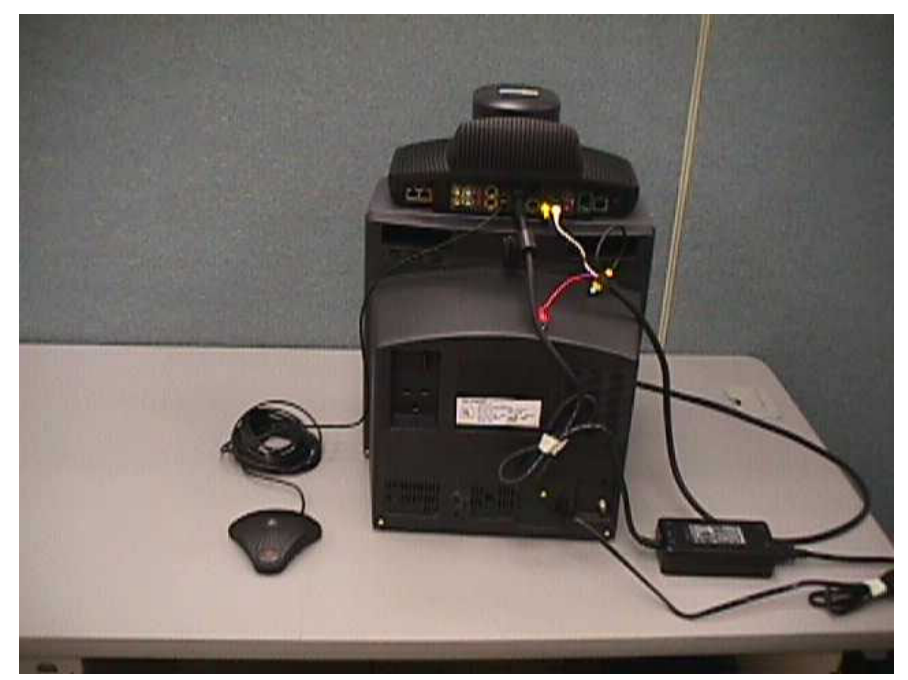

Figure 28. ViewStation with TV/VCR, power supply, and microphone attached

Finally, remove the rectangular interface box and cabling from the ViewStation case (Figure 29). The cable contains green RJ45 connectors on each end. Attach one end of the cable into the green color-coded jack on the interface box and the other end of the cable to the green color-coded jack on the rear of the ViewStation as shown in Figure 30. 


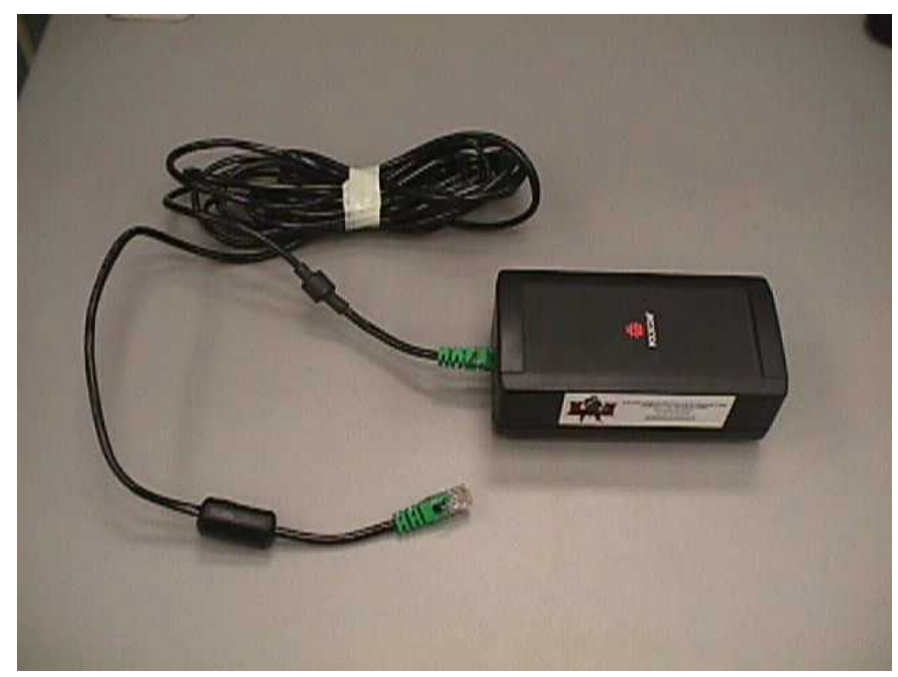

Figure 29. ViewStation rectangular interface box and cabling

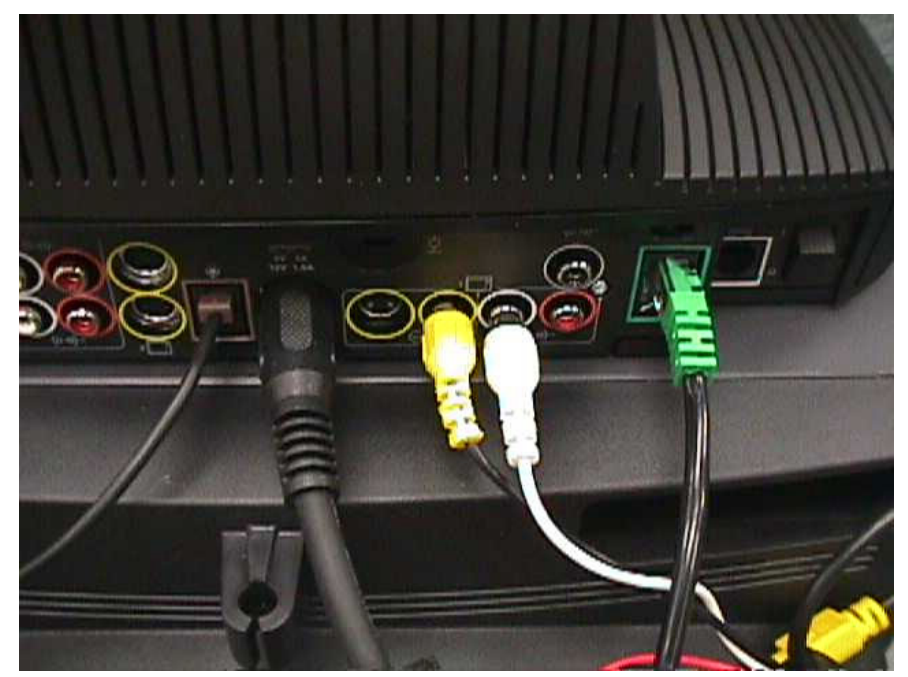

Figure 30. Connection of the ViewStation rectangular interface box

The other end of the interface box contains two 25-pin female connectors. The port labeled " 1 " connects to the "B" port on the switchbox. Figure 31 provides an illustration of the connections made thus far. More details on the switchbox connection are provided later in this chapter.

The last item to be removed from the ViewStation case is the remote control. Its use and operation will be presented later in the operation portion of this document. 


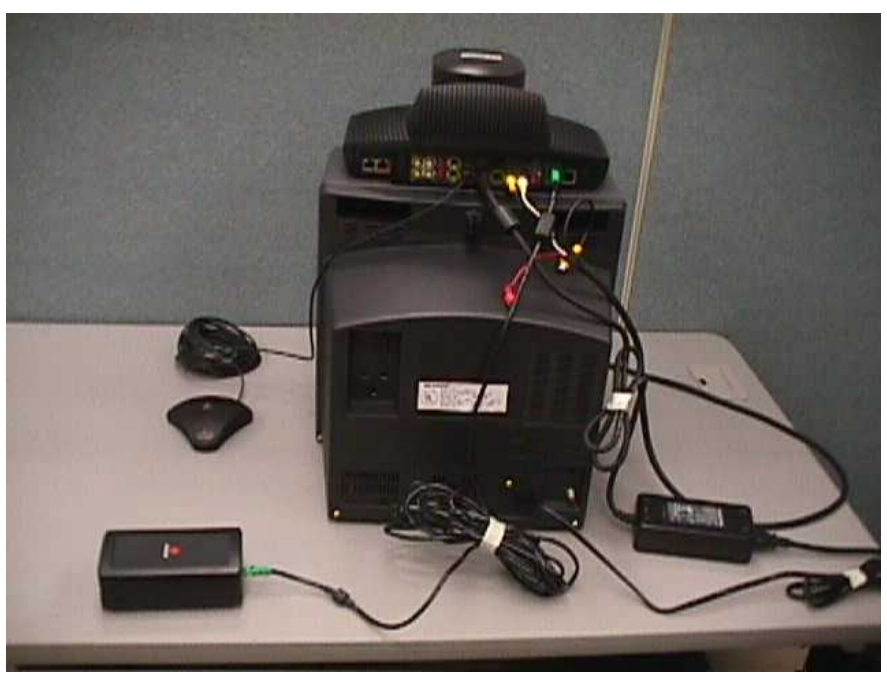

Figure 31. ViewStation, TV/VCR, power supply, microphone, and interface box attached

\section{SPOCC}

Place the SPOCC on a sturdy, stable surface large enough to accommodate the size of the case when opened and laid flat. Open the case and notice the slot for the STU-III, the power subsystem, and the laptop computer with a printer/ scanner (Figure 5). If available, install the STU-III phone by placing the handset in its position. Typically, there should be three cables already connected to the rear of the STU-III; these include an RJ11 phone line, the data ribbon cable, and the eight-pin power connector. In order to use the STU-III phone, a telephone cable with RJ connectors on each end will need to be connected from the line-in jack on the SPOCC to a rear jack on the INMARSAT IDU. The phone jack on the IDU is labeled "J1." The STU-III phone can now be used instead of the IDU handset phone; however, the IDU handset will remain active.

The SPOCC printer can function as a scanner (Figure 32) by replacing the print cartridge with a scan cartridge. Connect the printer cable to the parallel port on the laptop as shown in Figure 33.

The printer turns on when the SPOCC power system is activated.

The laptop is held in place with Velcro straps. Remove the Velcro straps, fold out the laptop platform section, position for use, and open the laptop lid. The power cord for the laptop must be connected. The cord is secured inside the case; its connection is illustrated in Figure 34.

When securing the laptop after use, the power cord and printer cable must be disconnected to prevent damage to the connectors. 


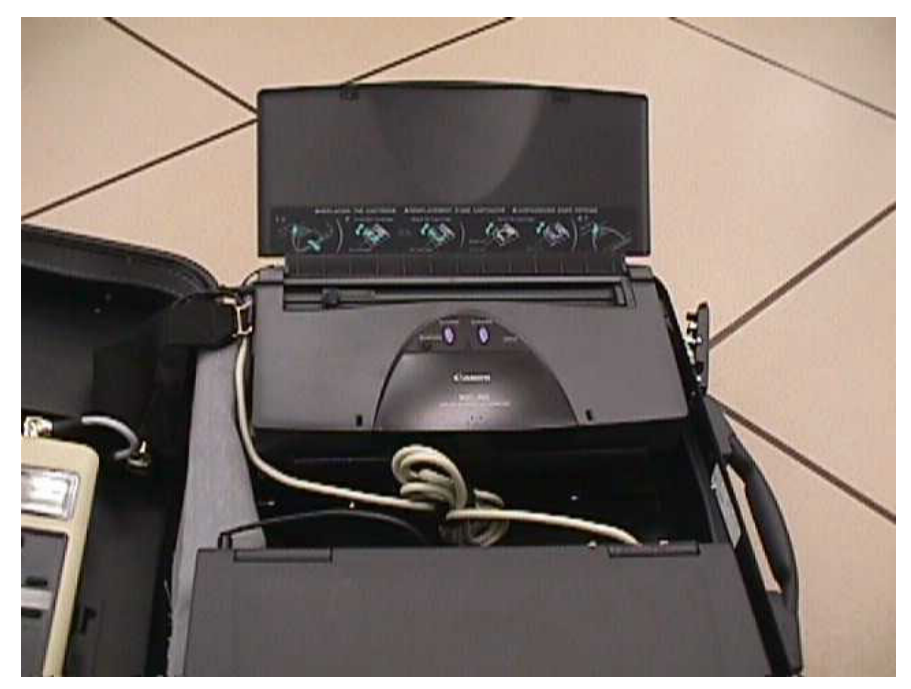

Figure 32. SPOCC Printer

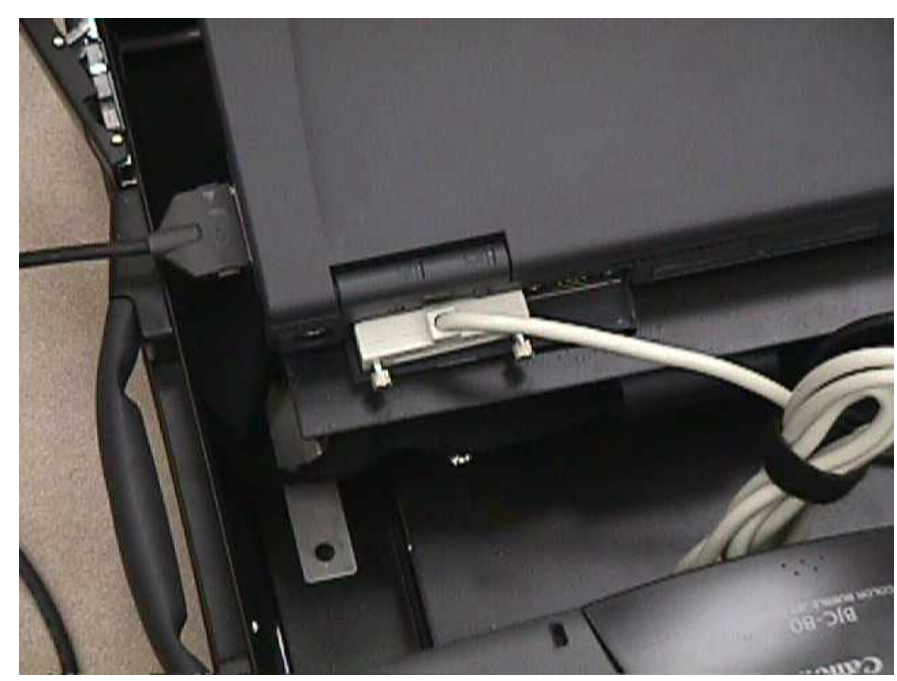

Figure 33. Parallel printer cable connected to the laptop 


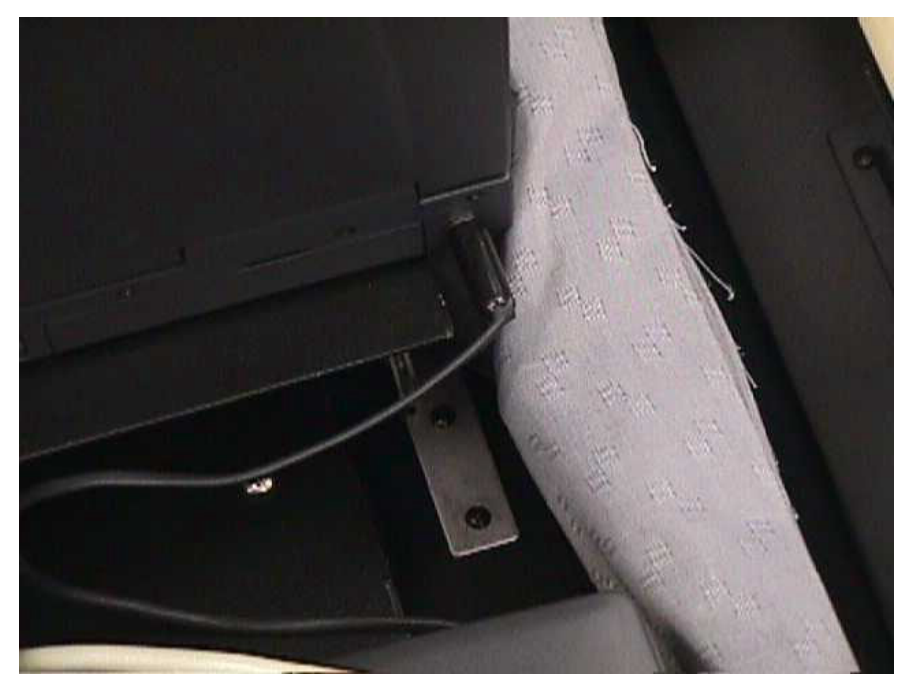

Figure 34. Power cord connected to the laptop

The laptop has been configured with a PCMCIA card and software for transferring data. Typically, the card is already installed; however, if the card is not installed, simply insert the card in a card slot on the right side of the laptop as shown in Figure 35.

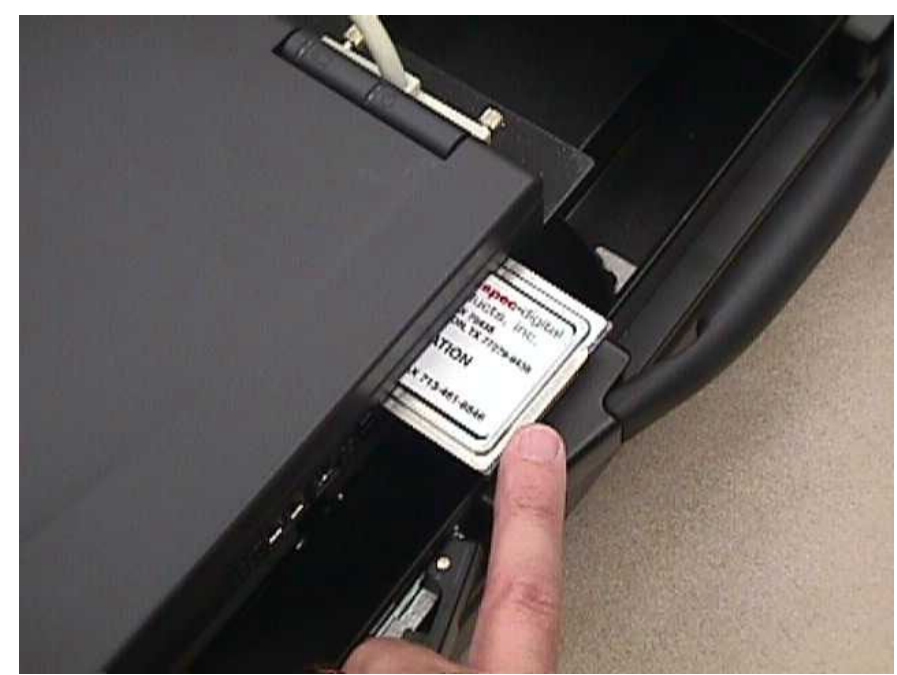

Figure 35. Insertion of Comspec card into laptop

This card is designed to transmit and receive data in high noise (interference) environments such as wireless/satellite-based systems. A cable must be connected from the PC card to the line converter. This cable has a connector with a label identified as Comspec DPI; this label must be placed facedown and plugged into the PC card as shown in Figure 36. 


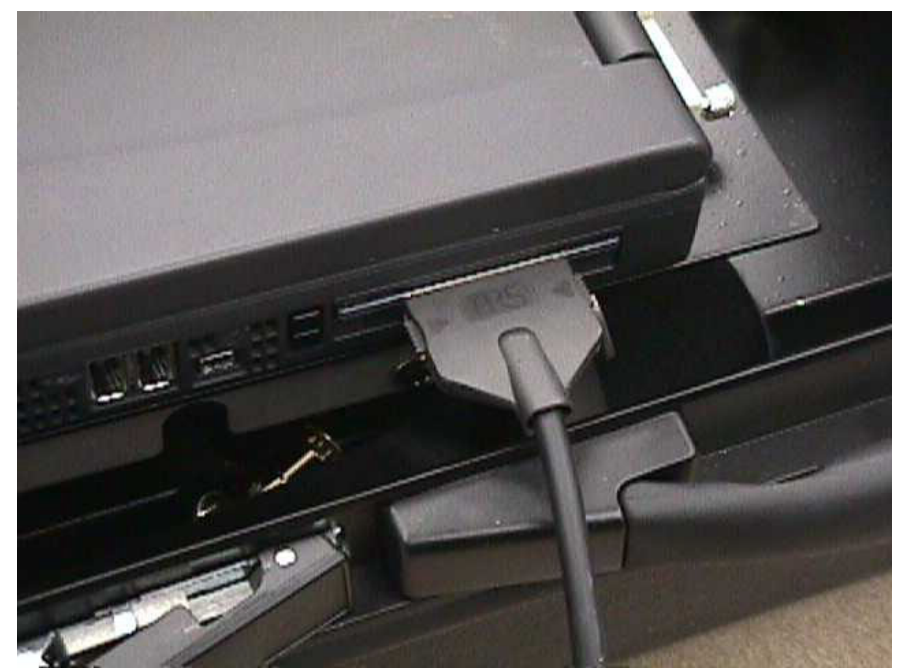

Figure 36. Comspec DPI cable connected to PCMCIA card

The other cable connector end must be plugged into the line converter. A cable from the line converter with a 25-pin female connector must be plugged into the data cable connected to port "A" of the A/B switchbox as illustrated in Figure 37.

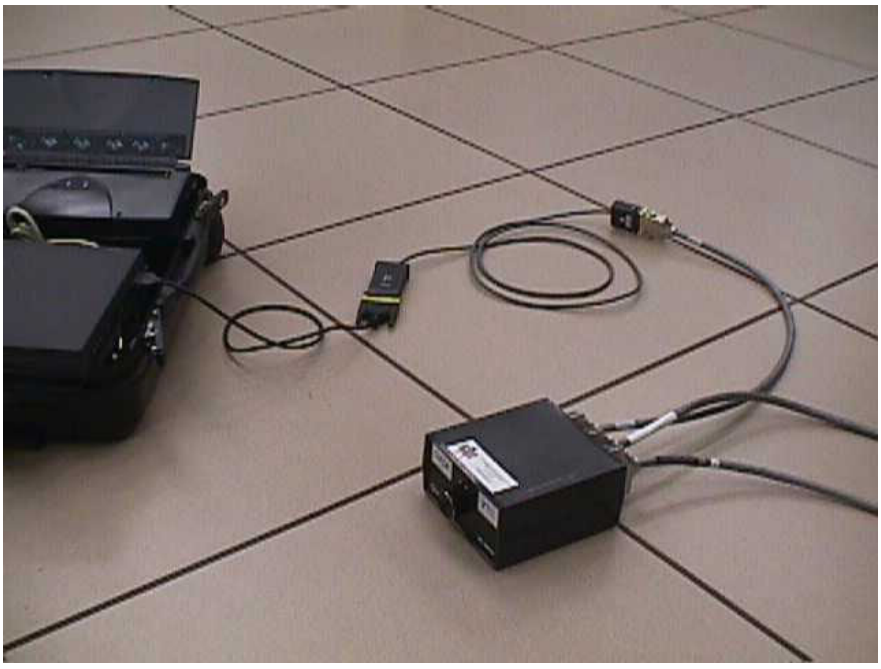

Figure 37. SPOCC Comspec cable connection to the switchbox

\section{KIV-7HS, Switchbox, Cables, and Miscellaneous Parts}

Remove the KIV-7HS (KIV), KIV power supply, A/B switchbox with data cables, and power strip from one of the large gray plastic cases. If using vehicle power, remove the extension cord, ProSine power converter, and battery jumper 
cables. Figure 38 illustrates the KIV, KIV power supply, switchbox, and data cables.

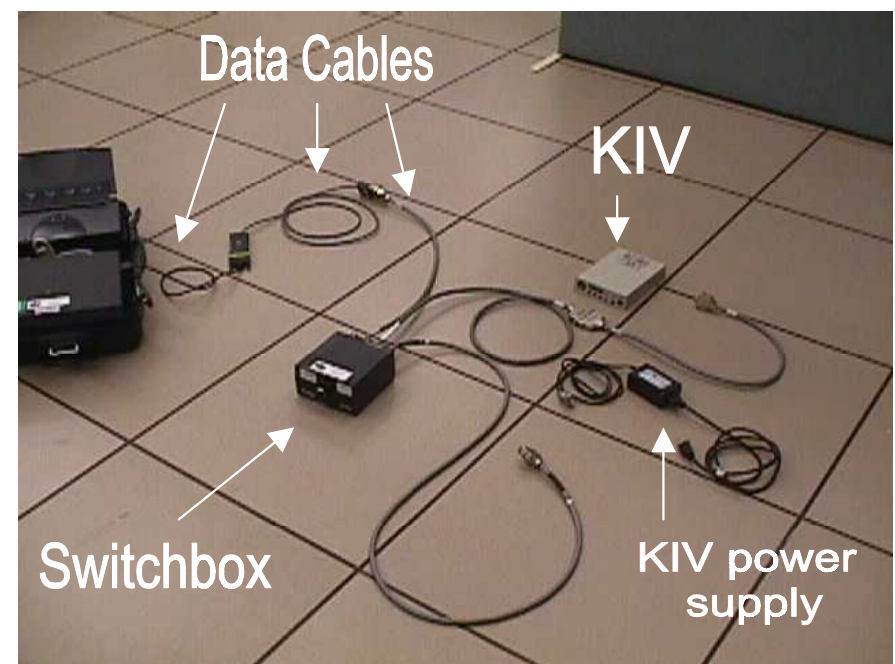

Figure 38. KIV, KIV power supply, switchbox, and data cables

The KIV is usually packaged in a cardboard box. When removing the KIV from its box, be careful not to accidentally "zeroize" the unit. "Zeroizing" the unit deletes all loaded encryption keys, thus rendering the unit useless for secure communications. The KIV can be "zeroized" by simultaneously depressing two buttons on the front panel. The user should always handle the KIV by the sides of the housing to avoid accidental "zeroizing," even when power is not connected.

There are four (4) ports located on the rear of the KIV. Three of the ports are labeled from left to right as "Red," "Black," and "Power." Each port accepts a 37-pin male, 37-pin female, and 9-pin female connector, respectively. Connect the KIV power supply to an AC power source. A 220 VAC power cord and a $110 \mathrm{VAC}$ power cord have been provided for use, depending on the available power; use the appropriate cord. Connect the other end, a 9-pin female connector, into the rear of the KIV at the port labeled "Power" as shown in Figure 39.

The switchbox is used to select either the VTC mode or data communications mode. The switchbox contains a two-position selector knob; the positions are labeled "A" (for data) and "B" (for VTC). Position A enables data communications; position B enables VTC communications (Figure 40).

There are three (3) ports located on the rear of the switchbox. Each port will accept a 37-pin male connector; the ports are labeled from left to right as B, C, and $\mathrm{A}$.

Typically, three data cables are already attached to the switchbox when the system is delivered. Only connecting the other end of each cable is necessary; 


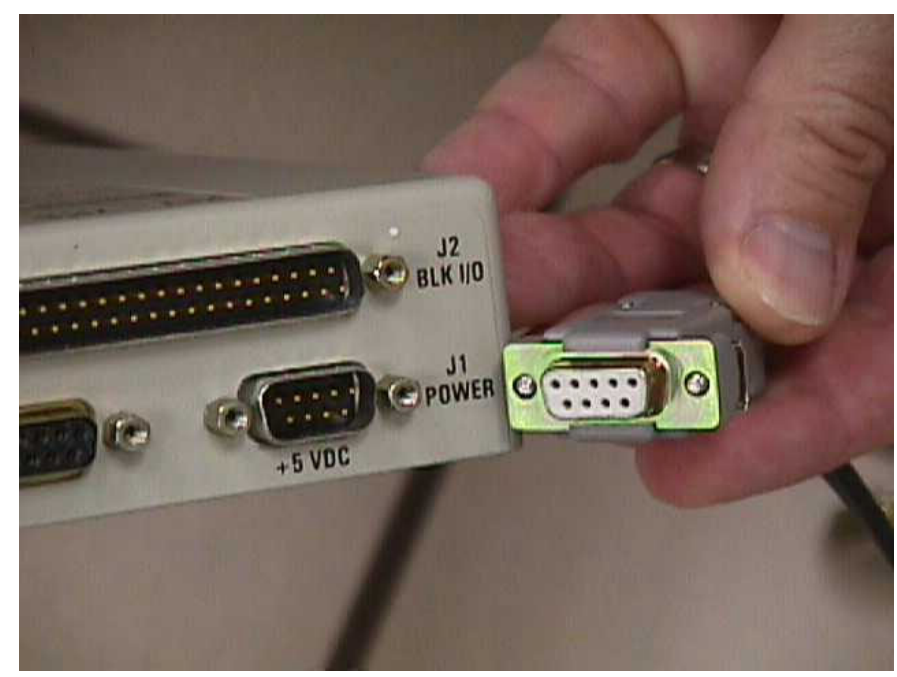

Figure 39. Nine-pin power connection on KIV

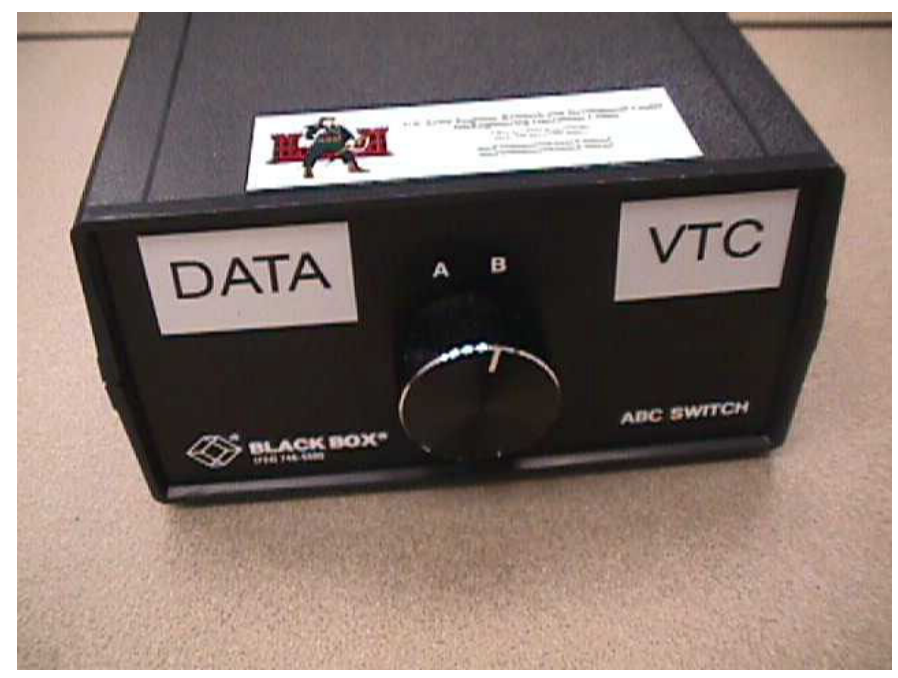

Figure 40. Front of switchbox

however, for clarity, each cable and its connection will be presented in the following paragraphs:

a. Cable 1 connects the switchbox and two other cables to the SPOCC (Figure 41). The two cables, the Comspec DPI cable and the line converter cable, were discussed in the section describing the setup of the SPOCC. Cable 1 contains a 25-pin male connector and 37-pin male connector. The 37-pin male connector plugs directly into Port A on the rear of the switchbox. The 25-pin male connector plugs into the line converter which connects to the Comspec DPI cable.

b. Cable 2 consists of a 25-pin male connector and 37-pin male connector (Figure 42). The 37-pin male connector plugs directly into Port B on the rear of the switchbox. The other cable end, a 25-pin male connector, 


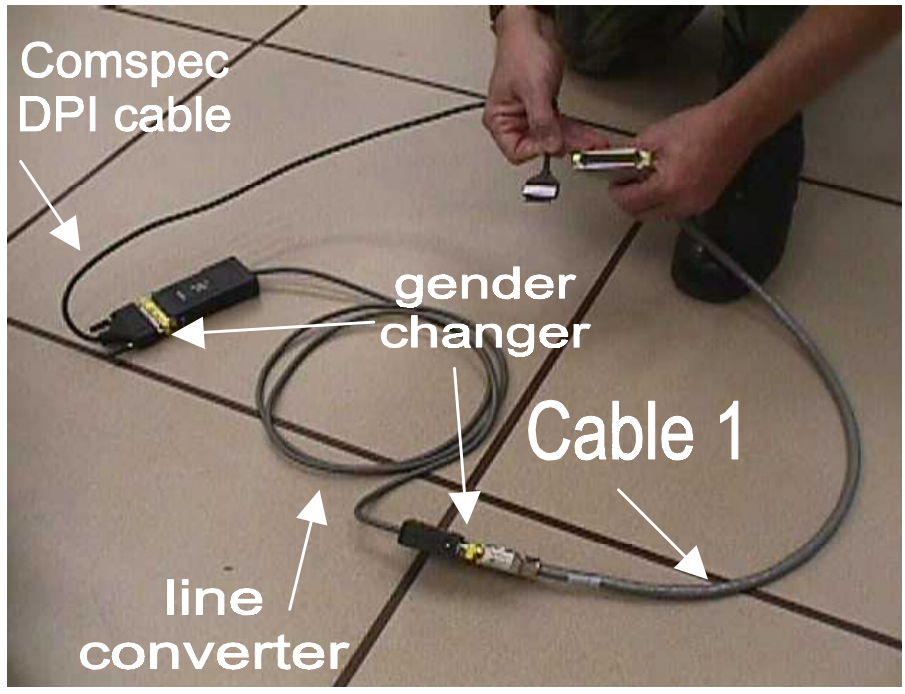

Figure 41. Cable 1 and SPOCC data cables

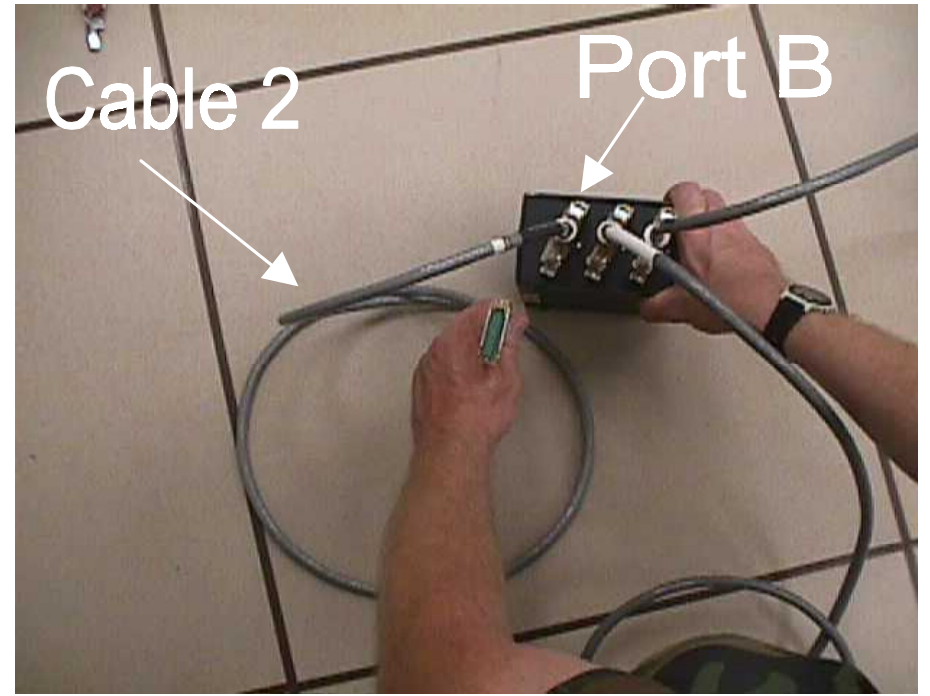

Figure 42. Cable 2

plugs directly into the ViewStation interface box. The box contains two ports; always use Port 1. The opposite end of the interface box has a green RJ45 jack which has already been connected to the ViewStation in earlier steps of this setup.

c. Cable 3 contains a 37-pin male connector on each end (Figure 43). One 37-pin male connector plugs directly into Port $\mathrm{C}$ on the rear of the switchbox; the other end, a 37-pin male connector, connects directly into the KIV Red Port located on the rear of the KIV. Exercise caution not to accidentally "zeroize" the KIV when connecting the cable. Always handle the KIV by the sides to avoid accidental "zeroizing." 


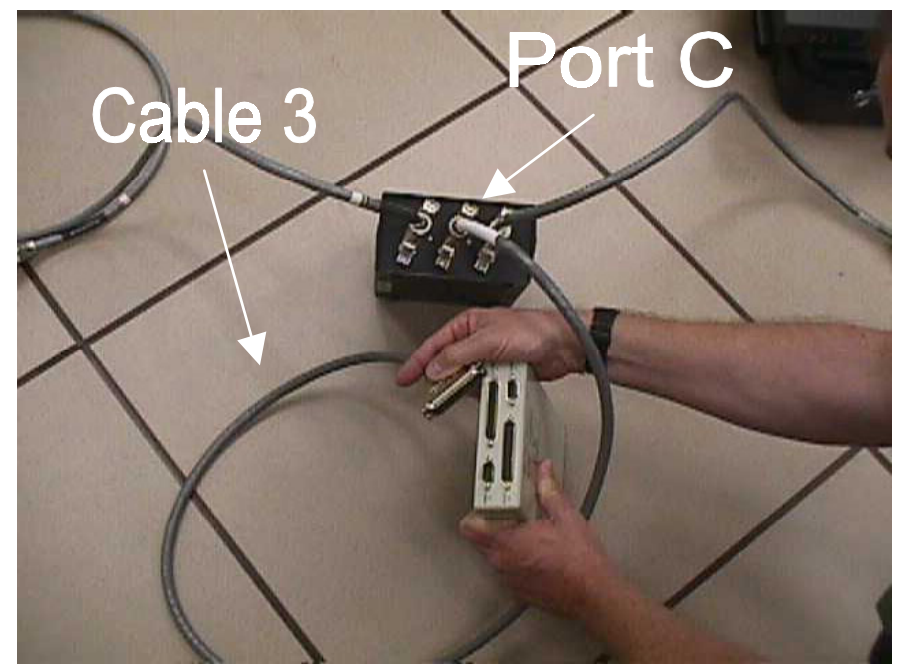

Figure 43. Cable 3

d. Cable 4 contains a 25-pin male connector and 37-pin female Connector (Figure 44). The 37-pin female connector plugs directly into the KIV Black Port on the rear of the KIV.

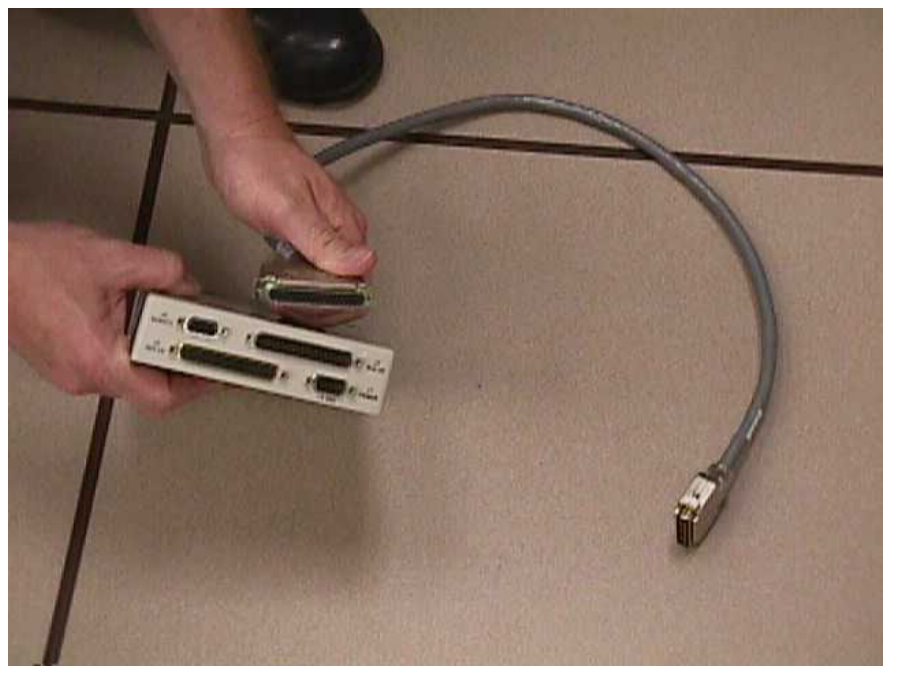

Figure 44. Cable 4

The 25-pin male connector plugs directly into the rear port of the IDU. Insert the connector into the port labeled SYNC PORT on the top and 56/64 HSD on the bottom. Using a screwdriver, secure all cables. 


\section{Hand-held Camera}

The Panasonic Palmcorder with Photoshot provided with this system has an audio/visual output jack (A/V OUT) located on the right side of the camera, near the palm rest of the camera (Figure 45).

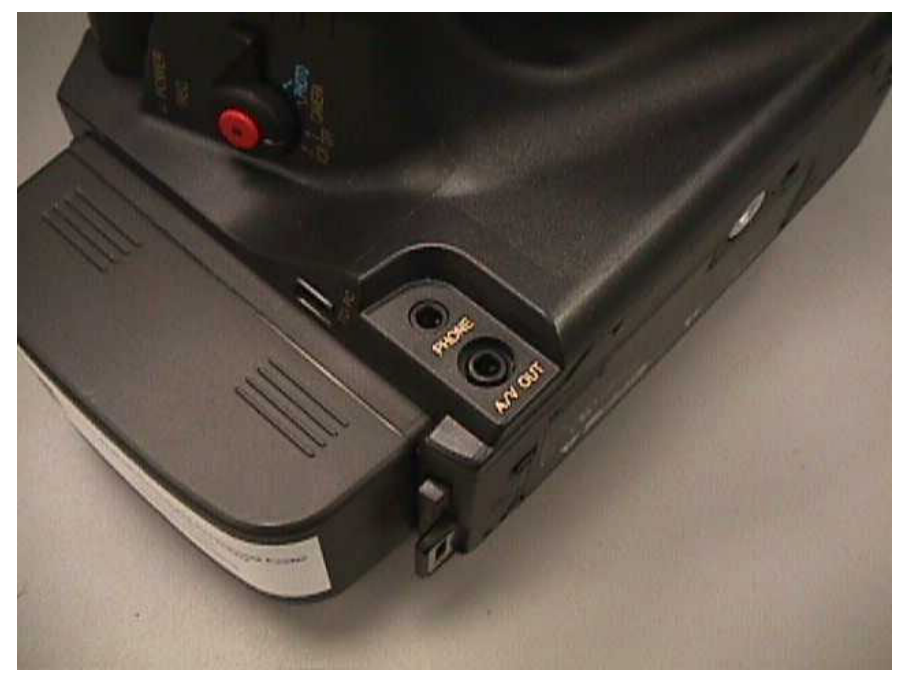

Figure 45. Location of the A/V OUT jack on the Palmcorder

The cable used to connect this camera to the ViewStation has two RCA plugs on one end, with a single male connector on the other end. Figure 46 illustrates this cable.

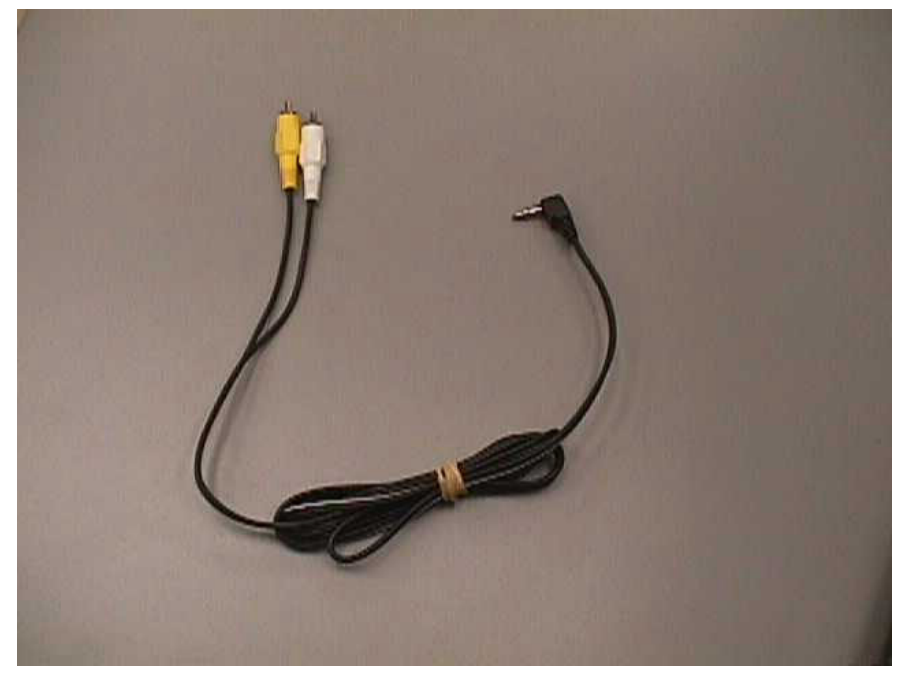

Figure 46. Cable for Palmcorder connection to the ViewStation 
Connect the single male connector to the A/V OUT jack on the camera. Connect the color-coded RCA plugs into the color-coded VCR jacks on the left rear of the ViewStation. Figure 47 illustrates the connections on the ViewStation.

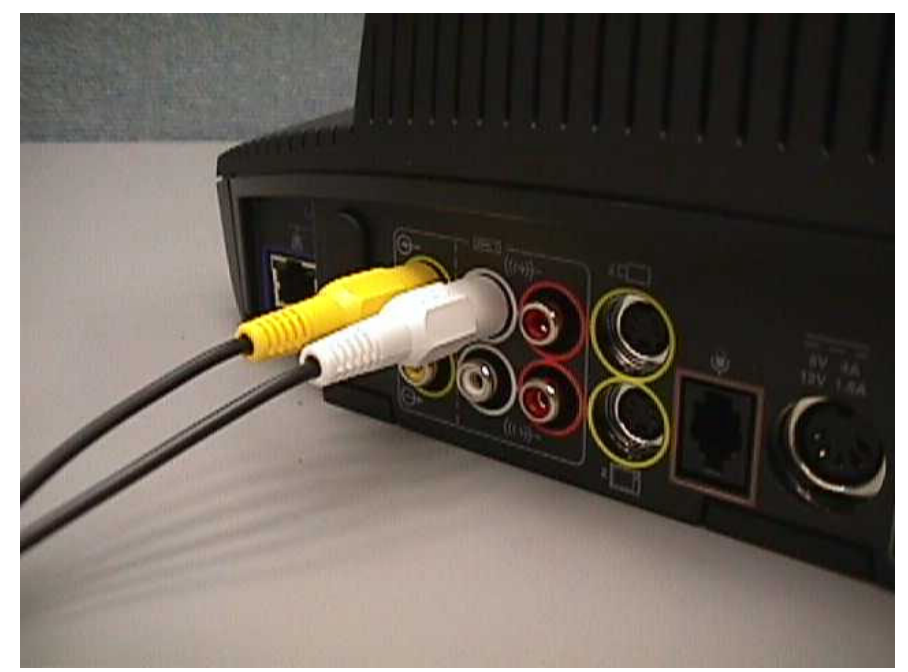

Figure 47. Cable Connections on the ViewStation

Ensure that the camera's battery is fully charged before operation. For more details on the setup of the camera, refer to the manufacturer's documentation.

Remember, setting up the hand-held camera is not necessary for normal operation of the VTC.

\section{Power Sources}

The system is designed to operate on a $110 \mathrm{VAC}$ power source or on a 220 VAC power source, with the exception of the TV/VCR; it operates only on $110 \mathrm{VAC}$. A $110 \mathrm{VAC}$ surge protector power strip is provided for connecting all of the components capable of $110 \mathrm{VAC}$ operation. A $220 \mathrm{VAC}$ power strip may also be furnished with the system.

If only DC power, like that of a $12 \mathrm{VDC}$ automotive system, is available, the ProSine power convertor can be used to convert the 12 VDC to 110 VAC with sufficient current to operate all system components.

To use the inverter, ensure that the ProSine's power switch is in the "OFF" position. Using the automotive battery jumper cables, connect the positive terminal on the rear of the ProSine to the positive terminal of the vehicle's 12 VDC battery; connect the negative terminal of the ProSine to the negative battery terminal. Crank the vehicle and turn the ProSine "ON." Never crank the vehicle with the ProSine in the "ON" position. 
Connect the 110 VAC power strip to the ProSine; connect the system components to the power strip. With the power strip power turned "ON," power up the system components, starting with the INMARSAT-B terminal. 


\section{Operation of the System}

\section{Making a Voice Call}

The IDU supports nonsecure voice communications. Instructions for placing voice communications (telephone calls) are located on the IDU front panel and the setup sheet.

To place a telephone call:

a. Lift the handset located on the left side of the IDU.

$b$. Listen for a dial tone.

c. When a dial tone is detected, dial $00+$ country code + area code +7 -digit number + "\#." The country code is " 1 " for the United States, " 49 " for Germany, and " 82 " for Korea. To dial the TEOC, for example, dial "00 16016343485 \#” or "00 16016344231 \#."

If a STU-III is available and installed in the SPOCC, voice calls can be initiated from the STU-III. The same dialing sequence used from the IDU is used to place a call from the STU-III. For example, dial $00+$ country code + area code + 7 digit telephone number + "\#” to place a voice call. If the user and recipient are both using STU phones, you can initiate the secure call by pushing the "SECURE" button on the STU-III as illustrated in Figure 48.

After pressing the "SECURE" button, verify that the call is secure by reading the message on the STU LCD. If only one party is using a STU phone, then the communications are nonsecure.

\section{Conducting a VTC}

To initiate a secure VTC, ensure the switchbox selector knob is positioned to VTC or "B." Power the ViewStation by positioning the rocker switch on the right rear side of the ViewStation to the "1" position. Turn on the TV/VCR and ensure the channel (input) selection mode is "INPUT." A start screen should appear on the TV. 


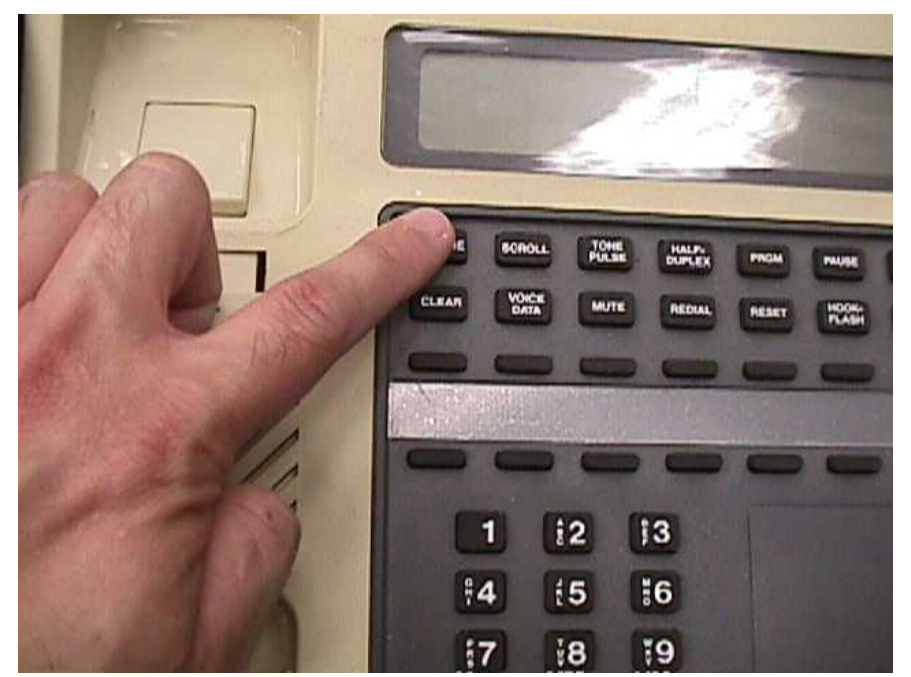

Figure 48. Pressing the SECURE button on a STU-III

Various functions of the TV and ViewStation can be controlled with the remote control (Figure 49).

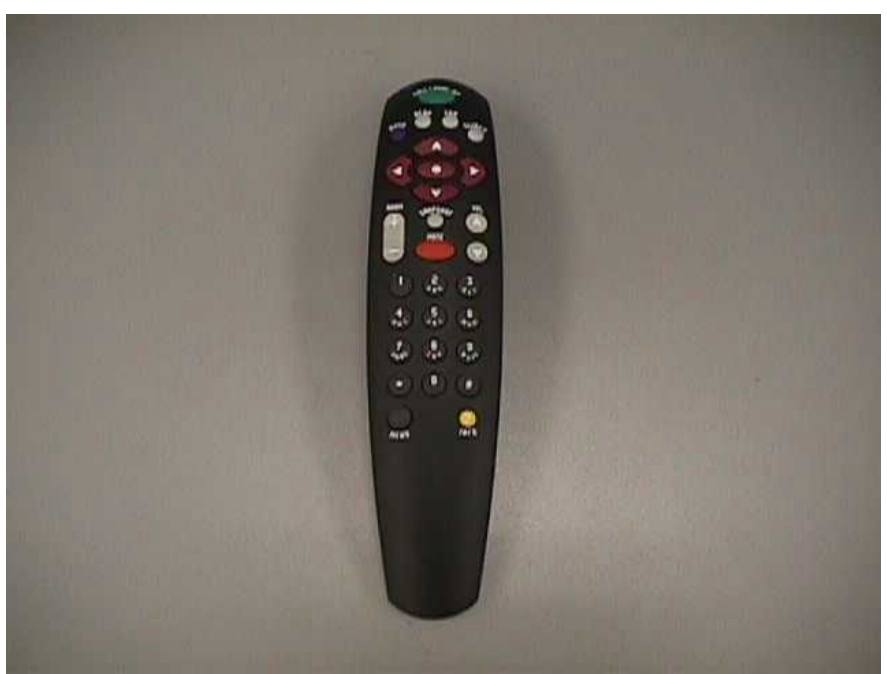

Figure 49. ViewStation remote control

Some of the more commonly used keys on the remote control are:

a. Volume key. Located on the right side, increases or decreases the volume output of the ViewStation.

b. Green key. Located at the top of the remote control; selects from a start screen to a full screen and vice versa. Prior to conducting a VTC conference call, this key can be used to select a full screen which activates the ViewStation to display the view from the ViewStation's camera. The key is also used to make screen selections. 
c. Red arrow keys. Located near the top of the remote control; after a full screen has been activated, the keys can be used to rotate the ViewStation camera to obtain a desired view.

d. Zoom key. Located on the left side and is used to "zoom" the ViewStation camera.

Ensure that the KIV is connected properly. A crypto ignition key (CIK) is supplied with each KIV-7, which will only activate that particular unit. The CIK is illustrated in Figure 50.

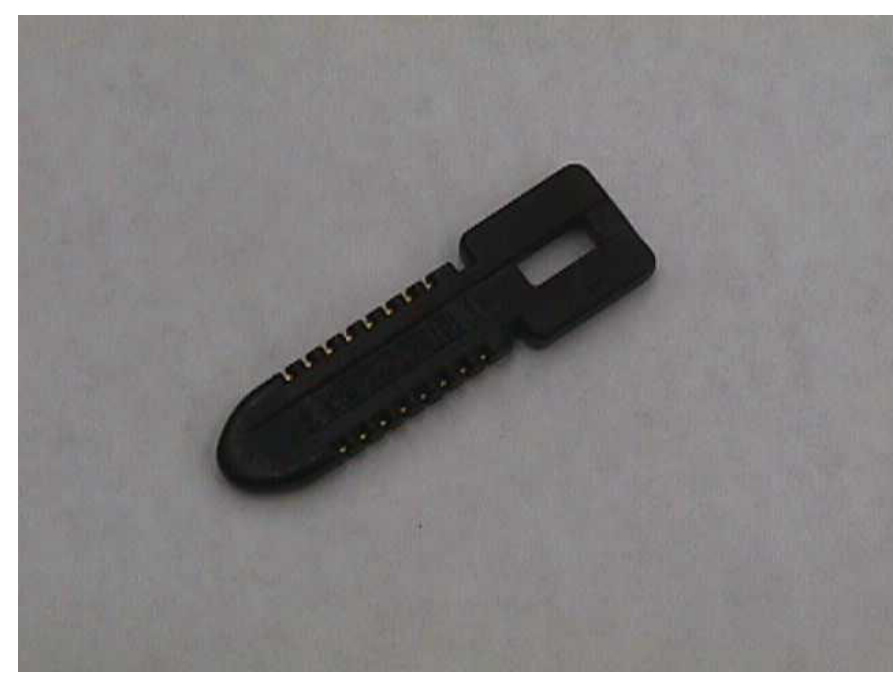

Figure 50. Crypto Ignition Key (CIK)

Insert the CIK into the slot located on the right front side of the KIV and turn the CIK to the horizontal position as shown in Figure 51. The KIV will "beep" and messages will appear on the KIV-7 display; messages appearing are as follows: "Testing," "Batt Good," "Key Good," and finally, "FDX." After the FDX message appears and remains in the FDX mode, the On-line button will flash, indicating the system is ready for a secure call. If the call is nonsecure, the KIV must be completely removed from the system by unplugging the two cables connected to the RED and BLACK ports of the KIV, and plugging the two connectors together.

Lift the handset from the IDU and dial the desired fixed-site number. All video and data communications require a high-speed data line; the fixed-site number must be preceded with "64." For example, a video call to the TEOC must be dialed as follows: "64 0016016343981 \#" (high speed line + $00+$ country code + area code +7 -digit telephone number + "\#."). Once the call is connected, the IDU display will indicate the dialed number and "CALL CONNECTED." If any other message is displayed, it may be necessary to hang up, wait approximately $15 \mathrm{sec}$, and redial the number, either manually or via the redial button. If the IDU display shows "CALL CONNECTED," press the green button at the top of the ViewStation remote control; this action will cause a full screen to appear on the TV. If the call is successfully placed and a connection is 


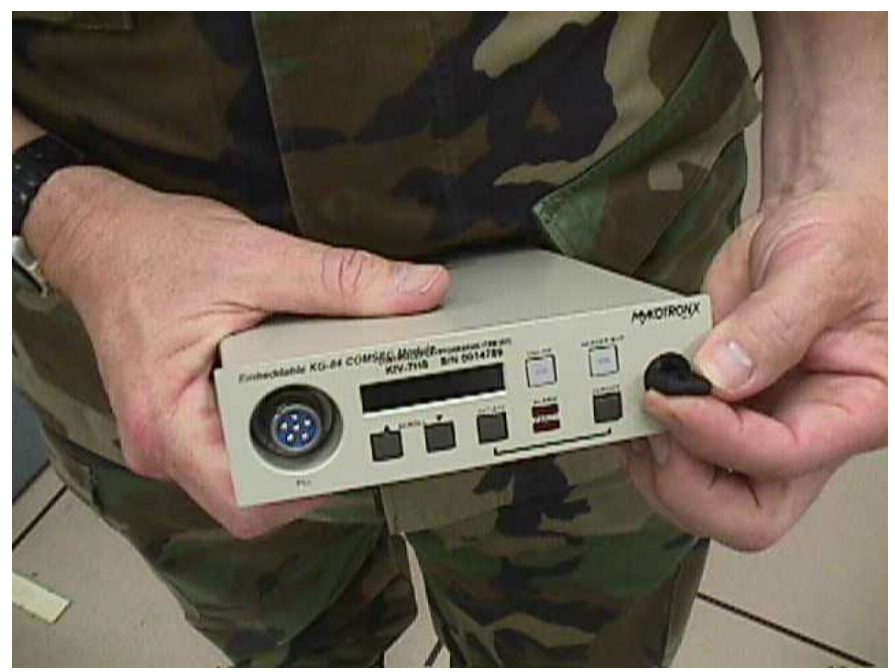

Figure 51. KIV with CIK inserted and turned to horizontal position

made with the fixed site, the KIV will beep twice indicating that the two systems are in contact. If the connection is successful, the far site will be displayed on the TV monitor. The entire process may take up to $60 \mathrm{sec}$ for the far site to be displayed. Lightening bolt icons may be displayed on the TV monitor during the call if signal interference is encountered. If the problem does not correct itself within a few minutes, terminate the call; try to increase the signal strength by moving the satellite antenna, and then redial.

\section{Transferring Data}

The following paragraphs provide instructions on transferring and receiving files to/from remote sites.

Boot the PC. If the PC is already running, ensure that the laptop hasn't "gone to sleep." Reboot if necessary. Place any files that you wish to transfer in the C:IXMIT $\backslash$ SEND directory using Windows utilities, or any other technique you wish. All files in the C: XXMIT $\backslash$ SEND directory will be transmitted, so, ensure that only the files desired for transmission reside in this directory.

On the Windows Desktop, double click on the yellow icon labeled "ffastestsPC", "PC-GOV", or "GOV" (Figure 52).

If this action does not produce a window, left click on the entry on the Windows toolbar that matches the icon label ("ffastestsPC," "PC-GOV," or "GOV"), as illustrated in Figure 53. 


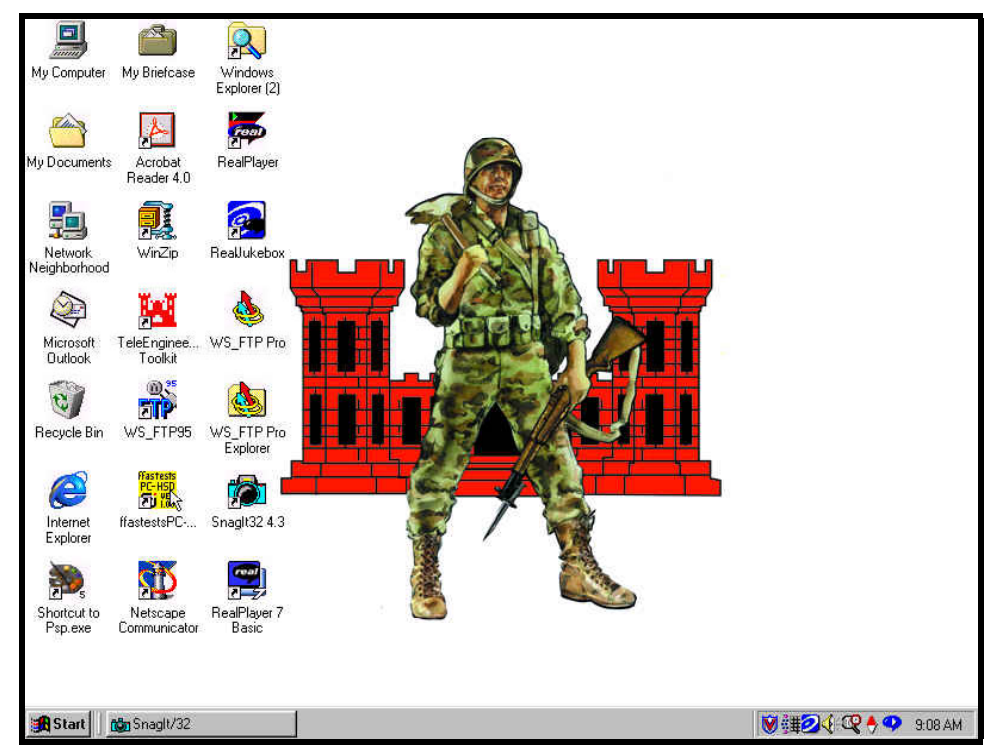

Figure 52. Desktop screen

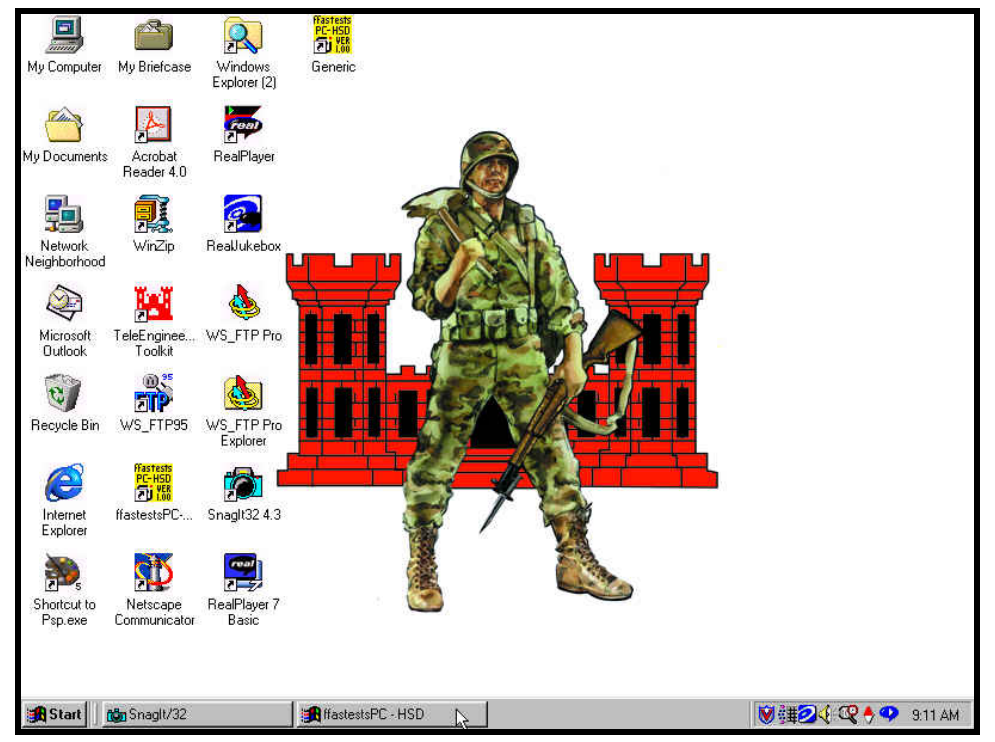

Figure 53. Activating ffastestsPC software

Click on "CONFIGURE" at the top of the window as illustrated in Figure 54. 


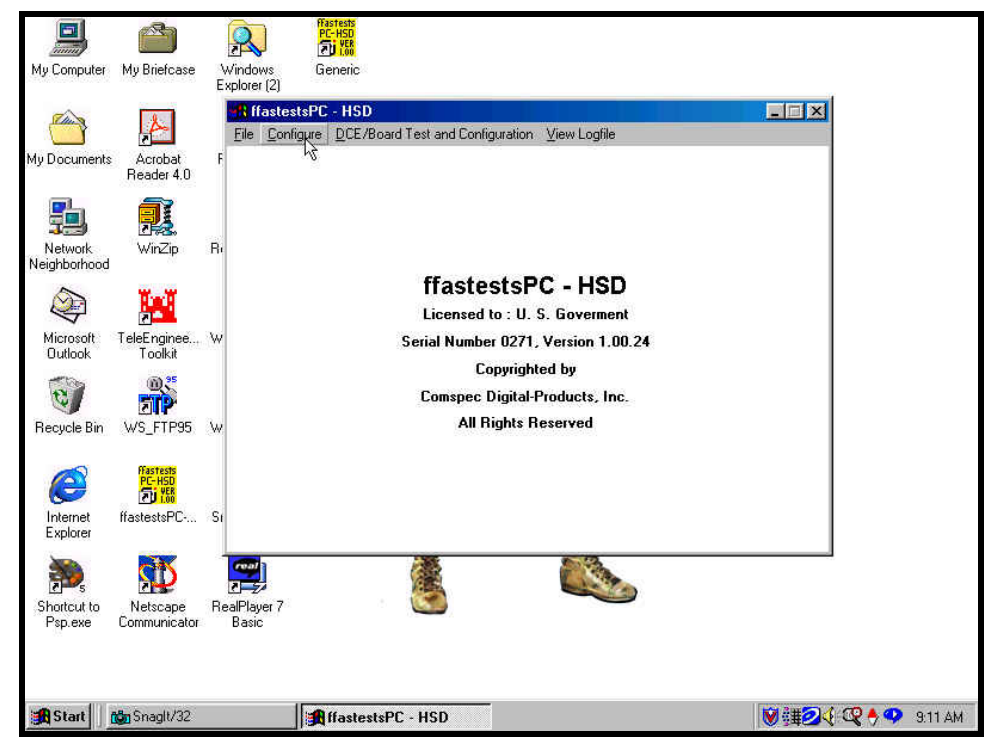

Figure 54. Configuring ffastestsPC software

At the next window, click on the "SEND" option as illustrated in Figure 55.

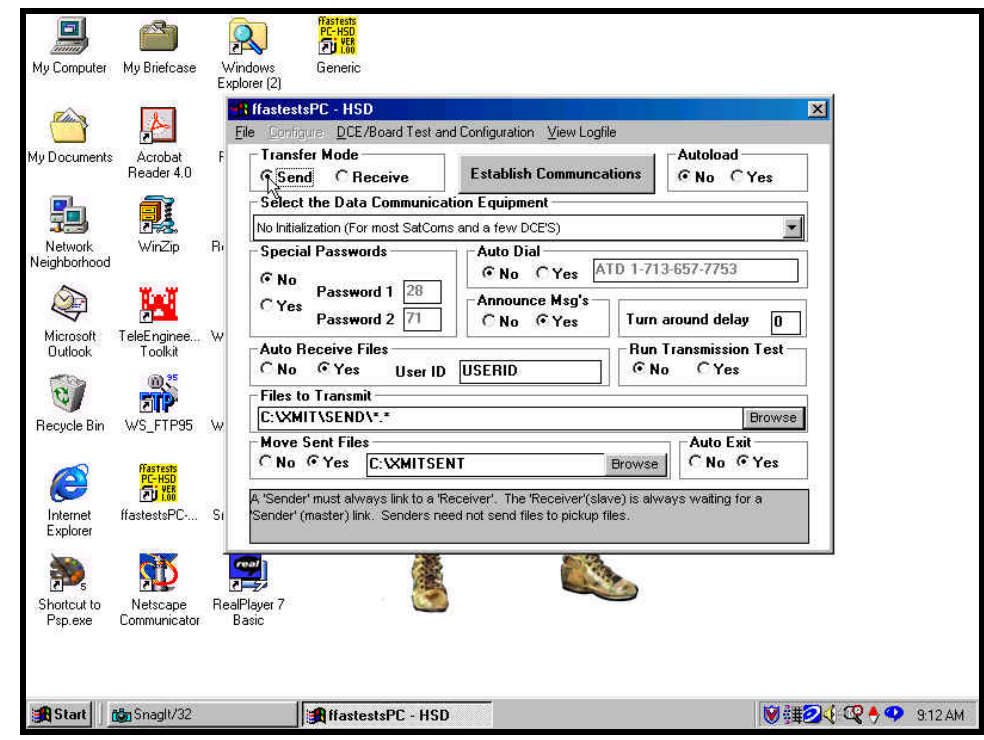

Figure 55. Activating "send" mode

The receiving system must be in the "RECEIVE" mode.

Enter your appropriate user identification (user ID). The default user ID is "USERID." When the call is actually connected and data files are transmitted, any files residing in the $\mathrm{C}: \mid \mathrm{XMIT} \backslash \mathrm{USERID}$ directory on the remote site will be transferred to your laptop in the C: $\backslash \mathrm{XMIT} \backslash \mathrm{RECV}$ directory, or whichever directory is specified on the configuration window. This file management system 
serves as a technique to prevent unauthorized users from obtaining data intended only for one specific user.

Press the "ESTABLISH COMMUNICATIONS BUTTON" on the window, as shown in Figure 56.

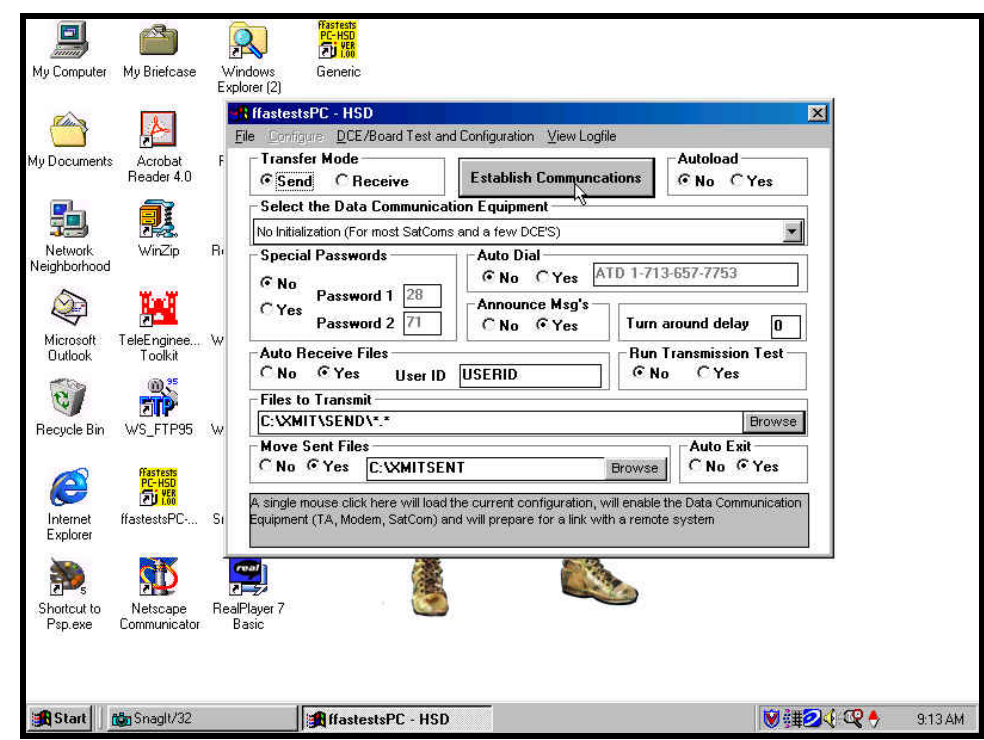

Figure 56. Establishing communications

A new window will appear. When the last line of text in the window reads "Trying to establish link," the laptop is ready for data transfer (Figure 57).

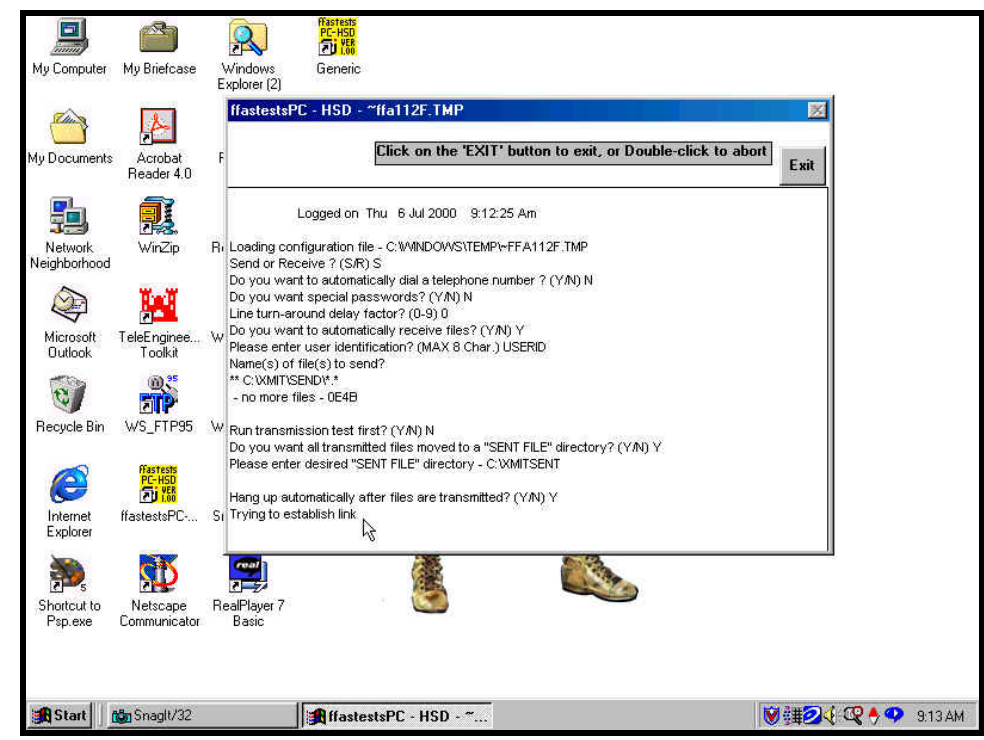

Figure 57. "Trying to establish link" window

Ensure that the CIK is inserted into the KIV and is turned to the horizontal position. The KIV display should read "FDX", and the online button should be 
flashing. Ensure the switch box knob is placed on "A" (DATA). Lift the IDU handset and dial the remote site. The dialing sequence for a high-speed data call is "64 + 00 + country code + area code + 7-digit telephone number + \#." Once the call is connected, the IDU will display the message "Call Connected." If any other message is displayed, terminate the call and try again. When the call is connected, the KIV will beep twice, indicating that it has synchronized with the other KIV. The message "Remote link established" will appear on the laptop. The file transfer process will begin automatically.

When the file transmitting and receiving have completed, hang up the handset on the IDU. Using the Windows utilities, look in your C: $\mid X M I T \backslash$ RECV directory to locate files that were received by your system. All transmitted files have been moved to your C: $\mid X M I T \backslash S E N T$ directory (or the directory specified on the original screen).

If the system loses satellite signal during transmission, only a portion of a file may be transmitted. The software is designed to complete the transmission on the next call. Simply establish communications and redial the call via the IDU.

\section{Digital Pictures (Hand-held Camera)}

Images with the digital camera provided can be transmitted over the system by three methods:

a. Directly connecting the camera to the ViewStation's VCR inputs, as shown in Figure 47 and selecting the camera as the ViewStation's input. This is accomplished by, while the system is in an active call, pressing the "Near" button on the ViewStation remote, and selecting the "VCR" icon to use the VCR input jacks as the input.

b. Directly connecting the camera as described in method a, and taking still shots with the camera. Use the "Play/Rec Photo" switch to recall digital pictures and display your picture. Ensure that the VCR jacks are selected as the input.

c. Taking a still image with the camera and downloading to the $\mathrm{PC}$ using the digital photo shop utility on the laptop. You may access the downloading software via the icon on the desktop. Connect the serial interface cable to the "To PC" jack on the camera and the other end to the serial port on the PC. 


\section{$5 \quad$ Getting Technical Support}

If you need support or would like to schedule a multi-point VTC, contact the TeleEngineering Operations Center (TEOC) at one of the following numbers:

1-877-223-8322 (toll free within US)

(601) 634-3485 (Commercial)

(601) 634-2735 (Commercial)

(312) 446-3485 (DSN)

(312) 446-2735 (DSN)

TEOC personnel respond to the voice mail at these numbers 24 hours a day, 7 days a week. Every reasonable effort will be made to assist you.

Questions may be emailed to the TEOC at:

teoc@teleengineering.usace.army.mil (nonsecure) teoc@teleengineering.army.smil.mil (secure)

You may visit our websites at:

http://teleengineering.usace.army.mil (nonsecure)

http://teleengineering.army.smil.mil (secure) 


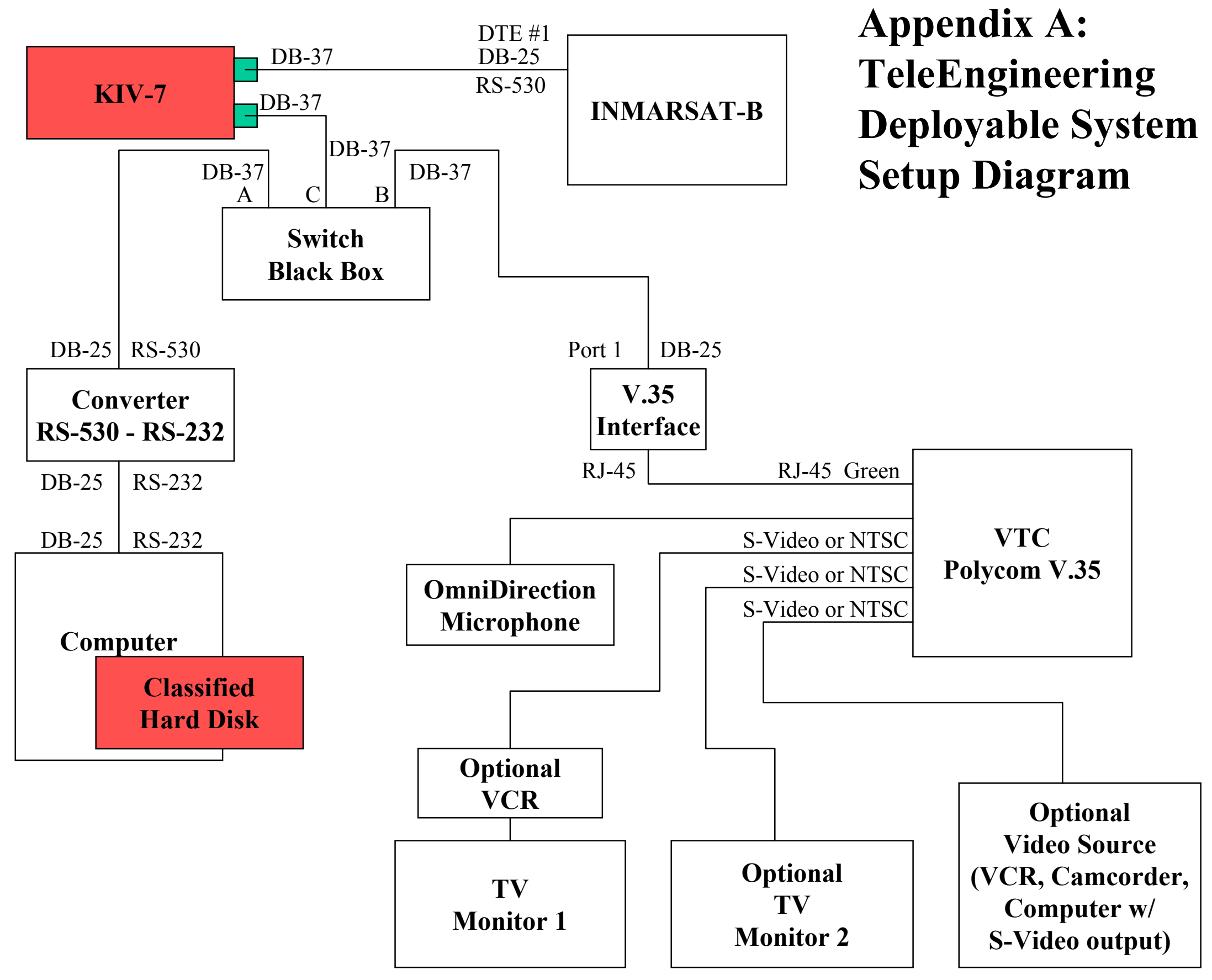




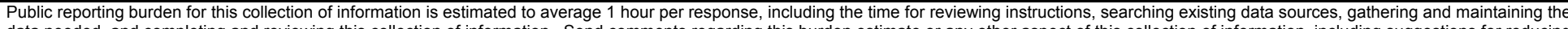

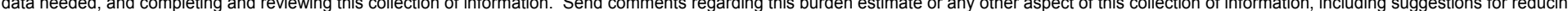

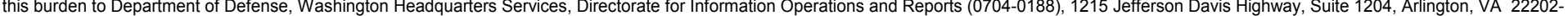

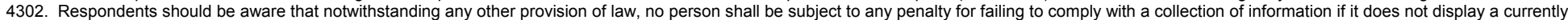
valid OMB control number. PLEASE DO NOT RETURN YOUR FORM TO THE ABOVE ADDRESS.

\begin{tabular}{l|l|l|l} 
1. REPORT DATE (DD-MM-YYYY) & 2. REPORT TYPE & 3. DATES COVERED (FrOm - TO)
\end{tabular}

August 2001

4. TITLE AND SUBTITLE

Final Report

Design, Setup, and Operation of the Deployable TeleEngineering Communications System

5a. CONTRACT NUMBER

5b. GRANT NUMBER

5c. PROGRAM ELEMENT NUMBER

6. AUTHOR(S)

5d. PROJECT NUMBER

Jeffrey L. Williamson, Carroll J. Smith, Larry N. Lynch, Jeff F. Powell

5e. TASK NUMBER

5f. WORK UNIT NUMBER

7. PERFORMING ORGANIZATION NAME(S) AND ADDRESS(ES)

8. PERFORMING ORGANIZATION REPORT NUMBER

U.S. Army Engineer Research and Development Center

Geotechnical and Structures Laboratory and

ERDC TR-01-6

Information Technology Laboratory

3909 Halls Ferry Road

Vicksburg, MS 39180-6199

9. SPONSORING / MONITORING AGENCY NAME(S) AND ADDRESS(ES)

10. SPONSOR/MONITOR'S ACRONYM(S)

U.S. Army Corps of Engineers

Washington, DC 20314-1000

11. SPONSOR/MONITOR'S REPORT NUMBER(S)

\section{DISTRIBUTION / AVAILABILITY STATEMENT}

Approved for public release; distribution is unlimited.

\section{SUPPLEMENTARY NOTES}

\section{ABSTRACT}

In FY97, the U.S. Army Engineer Research and Development Center (ERDC) initiated a technology demonstration program to determine the feasibility of providing deployed troops direct access to subject matter experts (SME). Direct access to the SME would allow responses to engineering challenges beyond the in-theater capability to be provided without the time delays and costs associated with deploying the SME to the theater. Shortly after being established, the TeleEngineering Operations Center (TEOC) initiated an effort to develop a secure, deployable communications package and steps necessary to set up and operate the system.

\section{SUBJECT TERMS}

Communication

INMARSAT-B

Reachback capability

Secure communications
TeleEngineering

Video-teleconferencing
16. SECURITY CLASSIFICATION OF:

a. REPORT

UNCLASSIFIED b. ABSTRACT

UNCLASSIFIED c. THIS PAGE

UNCLASSIFIED
17. LIMITATION OF ABSTRACT

\begin{tabular}{|c|l|}
$\begin{array}{c}\text { 18. NUMBER } \\
\text { OF PAGES }\end{array}$ & \begin{tabular}{l} 
19a. NAME OF RESPONSIBLE PERSON \\
\cline { 2 - 2 } 47
\end{tabular} \\
$\begin{array}{l}\text { 19b. TELEPHONE NUMBER (include area } \\
\text { code) }\end{array}$ \\
\hline
\end{tabular}

Standard Form 298 (Rev. 8-98)

Prescribed by ANSI Std. 239.18 